\title{
Q2 FY 2018 Progress Report on Ultrasonic Dehumidification: Milestone 2.1, Design of high-volume-density pores on sheets of material
}

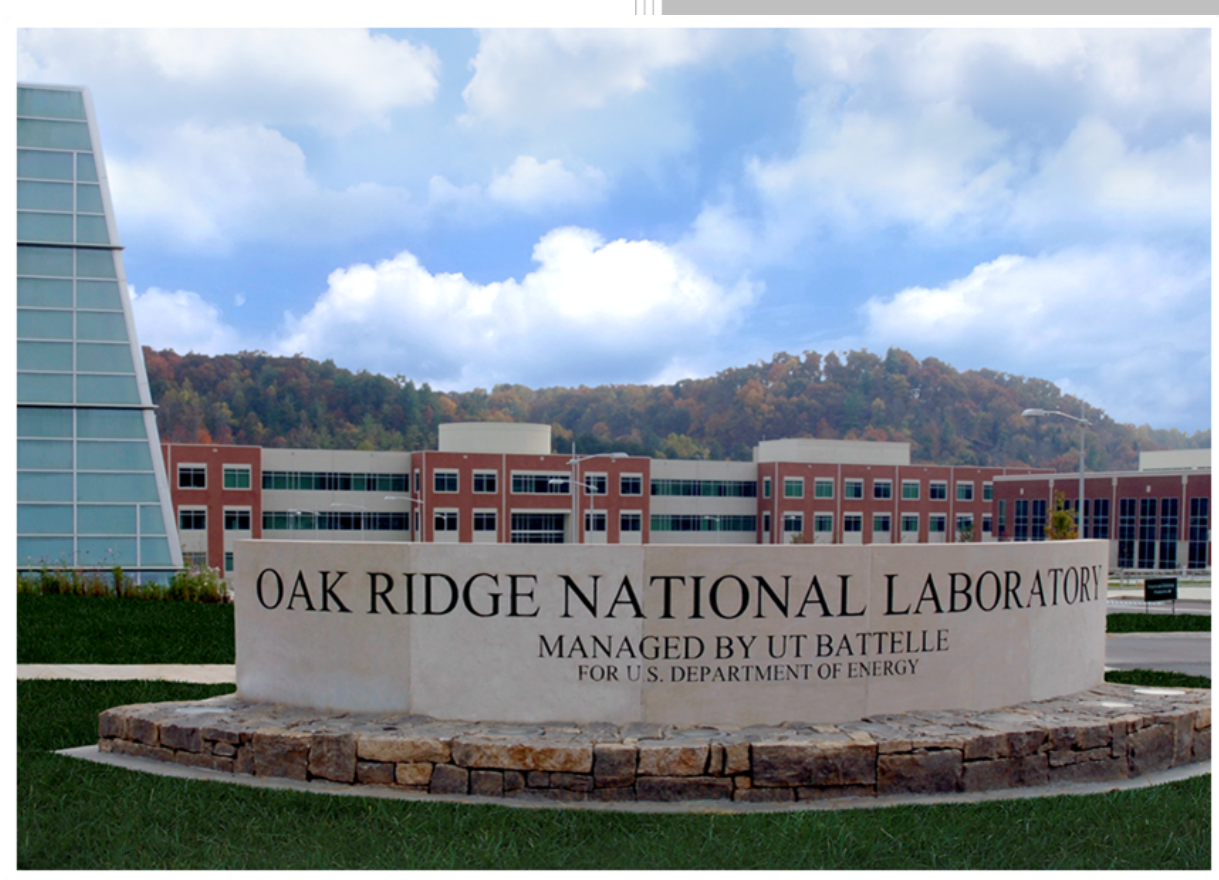

Approved for public release. Distribution is unlimited.
Ayyoub Momen Brian Bischoff Kashif Nawaz Eric Dupuis Viral Patel

March 31, 2018 


\section{DOCUMENT AVAILABILITY}

Reports produced after January 1, 1996, are generally available free via US Department of Energy (DOE) SciTech Connect.

Website www.osti.gov

Reports produced before January 1, 1996, may be purchased by members of the public from the following source:

National Technical Information Service

5285 Port Royal Road

Springfield, VA 22161

Telephone 703-605-6000 (1-800-553-6847)

TDD 703-487-4639

Fax 703-605-6900

E-mail info@ntis.gov

Website http://classic.ntis.gov/

Reports are available to DOE employees, DOE contractors, Energy Technology Data Exchange representatives, and International Nuclear Information System representatives from the following source:

Office of Scientific and Technical Information

PO Box 62

Oak Ridge, TN 37831

Telephone 865-576-8401

Fax 865-576-5728

E-mail reports@osti.gov

Website http://www.osti.gov/contact.html

This report was prepared as an account of work sponsored by an agency of the United States Government. Neither the United States Government nor any agency thereof, nor any of their employees, makes any warranty, express or implied, or assumes any legal liability or responsibility for the accuracy, completeness, or usefulness of any information, apparatus, product, or process disclosed, or represents that its use would not infringe privately owned rights. Reference herein to any specific commercial product, process, or service by trade name, trademark, manufacturer, or otherwise, does not necessarily constitute or imply its endorsement, recommendation, or favoring by the United States Government or any agency thereof. The views and opinions of authors expressed herein do not necessarily state or reflect those of the United States Government or any agency thereof. 
Energy and Transportation Science Division

\title{
Q2 FY 2018 PROGRESS REPORT ON ULTRASONIC DEHUMIDIFICATION: MILESTONE 2.1, DESIGN OF HIGH-VOLUME-DENSITY PORES ON SHEETS OF MATERIAL
}

\author{
Ayyoub Momen \\ Brian Bischoff \\ Kashif Nawaz \\ Eric Dupuis \\ Viral Patel
}

Date Published: March 31, 2018

Prepared by

OAK RIDGE NATIONAL LABORATORY

Oak Ridge, TN 37831-6283

managed by

UT-BATTELLE, LLC

for the

US DEPARTMENT OF ENERGY

under contract DE-AC05-00OR22725 



\section{CONTENTS}

\section{CONTENTS}

TABLE OF FIGURES

1. POROUS FILM STUDIES

1.1 COMMERCIALLY AVAILABLE AAO FILM

EIICS OF AAO FILM .........

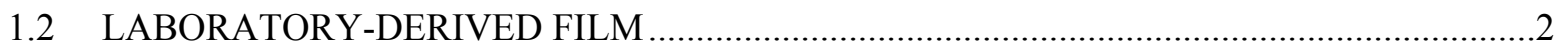

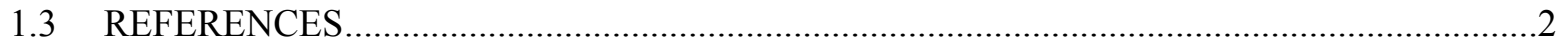

2. ULTRASONIC TRANSDUCER MODELING

.

APPENDIX A. MULTIPHYSICS MODELING OF MESH PIEZOELECTRIC TRANSDUCERS 


\section{TABLE OF FIGURES}

Figure 1. Moisture adsorption/desorption behavior of the AAO sample

Figure 2. Mass diffusion model domain

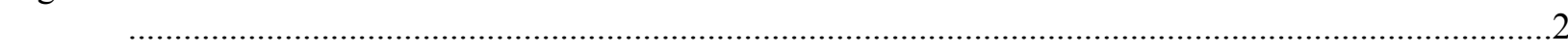

Figure 3. Photograph of dried xerogel

2

Figure 4. Thin plate undergoing harmonic base excitation about its circumference

(n)

Figure 5. a) FEM plate model. b) FEM transducer model

Figure 6. Acceleration FRF for the analytical and finite element plate model

Figure 7. Mounted transducer with reflective tape for LDV measurements

Figure 8. Acceleration FRF comparisons 


\section{EXECUTIVE SUMMARY}

During the second quarter of FY18, two potential candidate porous films for humidity removal via capillary condensation were studied: a commercially available Anodic Aluminum Oxide (AAO) film and a laboratory-derived porous film fabricated using sol-gel processing. Important experimental results were obtained for characterizing the moisture adsorption kinetics of the AAO film.

In addition to the membrane development, analytical and numerical models were developed that fundamentally described free and forced vibration of mesh piezoelectric atomizers. The details of the models and comparison of model predictions to experimental results are provided in Section 2 and in a conference publication (Appendix A).

The next step in the project is to determine the optimal moisture adsorption film for capillary condensation and combine it with a piezoelectric mesh transducer to determine the efficacy of ultrasonically enhanced desorption. 


\section{POROUS FILM STUDIES}

Both the pore size and the porosity are important attributes of the porous film to maximize the efficiency of humidity removal via capillary condensation. The pore size governs the vapor pressure of a condensable gas above a curved meniscus in capillaries filled with the condensed liquid. Capillary condensation is the process by which multilayer adsorption from the vapor phase into a porous medium proceeds to the point at which pores become filled with condensed liquid. A unique feature of capillary condensation is that condensation occurs below the saturation vapor pressure of the pure liquid. This result is due to an increase in the van der Waals interactions between vapor phase molecules inside the confined space of a capillary. Once condensation has occurred, a meniscus forms at the liquid-vapor interface which allows for equilibrium to be achieved below the saturation vapor pressure. Formation of the meniscus is dependent on the surface tension of the liquid and the shape of the capillary. The Kelvin equation (Equation 1) relates the ratio of the equilibrium vapor pressure $(\mathrm{P})$ to the saturation vapor pressure $\left(\mathrm{P}_{0}\right)$ as a function of the surface tension $(\gamma)$, molar volume $\left(\mathrm{V}_{\mathrm{m}}\right)$, Kelvin radius $\left(\mathrm{r}_{\mathrm{m}}\right)$, and the temperature $(\mathrm{T})$.

$$
\ln \left(\frac{P}{P_{0}}\right)=\frac{-2 \gamma V_{m}}{r_{m} R T}
$$

The Kelvin radius is related to the actual pore radius. The Kelvin radius plus the thickness of the multilayer adsorption layer at the point of condensation equals the pore radius. As can be seen from the Kelvin equation, the higher the surface tension, the lower the ratio of $\mathrm{P} / \mathrm{P}_{0}$. In other words, for high surface tension liquids such as water, the equilibrium vapor pressure is reduced more than it would be for low surface tension liquids. With respect to room air, the lower equilibrium vapor pressure translates into lower water content and thus lower humidity. In fact, for water, $\mathrm{P} / \mathrm{P}_{0}$ is the relative humidity. For a membrane with a pore size of $5 \mathrm{~nm}$, the Kelvin equation predicts a relative humidity of close to $50 \%$ at a temperature of $20^{\circ} \mathrm{C}$.

For this application, the porosity may also be important. The porosity, or the amount of open pores in a film or membrane, determine how much water can be pulled from the air before the pores need to be emptied. The film thickness may also play a role in how fast the filling and emptying can take place. To evaluate the ability to remove humidity, two porous films were investigated: a commercial porous membrane and a laboratory derived film, as described in the following sections.

\subsection{COMMERCIALLY AVAILABLE AAO FILM}

Porous membranes were purchased InRedox LLC. According to the vendor, they have a pore size of 10 $\mathrm{nm}$, a porosity of $12 \%$, and a thickness of 50 microns. Calculations were completed on the water adsorption data. Using porosity data supplied by the vendor, the membrane would be expected to absorb approximately $3.42 \%$ of the membrane's mass in water. Using the pore density, thickness, and pores size, the membrane would be expected to absorb approximately $3.62 \%$ of its mass in water. This compares to our measurements of $5.00 \%$. The difference is most likely due to adsorption that is in addition to capillary condensation.

Using the Kelvin equation for $10 \mathrm{~nm}$ pores, the $\mathrm{P} / \mathrm{P}_{0}$ at $25^{\circ} \mathrm{C}$ needed to fill the pores is 0.811 , or a $\mathrm{RH}$ of $81.1 \%$. Our tests were done at approx. $48 \%$ and $87 \%$ (Section 1.1.1). That means capillary condensation is expected in $10 \mathrm{~nm}$ pores at an $\mathrm{RH}$ of $87 \%$. A P/P $\mathrm{P}_{0}$ of around 0.35 is considered one monolayer of adsorption. Our result at 0.48 would be close. If we assumed that at $48 \% \mathrm{RH}$, only adsorption was taking place, we can subtract that from the total water uptake to get water from capillary condensation of $4.2 \%$ 
which is not far from theoretical prediction. Therefore, it is believed that we have capillary condensation consistent with approximately $10 \mathrm{~nm}$ pores.

\subsubsection{MOISTURE ADSORPTION KINETICS OF AAO FILM}

It is critical to understand the water vapor adsorption behavior of different films and desiccants as it can establish the time required to saturate the film and reach the maximum capacity of the system. Additionally, it is also important to understand the desorption behavior. The moisture adsorption experiments have been conducted to evaluate the performance of Anodized Aluminum Oxide (AAO) film. The experiments have been designed to evaluate the samples response when it is exposed to an immediate change in moisture content in the surrounding air. Figure 1 presents an experimental procedure. The sample was first dried for about 30 minutes to remove all the moisture and then exposed to immediate increase in relative humidity $(0 \% \mathrm{RH}$ to $45 \% \mathrm{RH})$. After equilibrium in the next test the relative humidity of the chamber was further increased (45\% to $85 \%)$. The transient and steady state response of the sample were recorded and were used to calculate the moisture diffusivity of the sample using appropriate model. As a next step the moisture content in the chamber was decreased in two steps ( $80 \% \mathrm{RH}$ to $45 \% \mathrm{RH}$ and $45 \% \mathrm{RH}$ to $0 \% \mathrm{RH}$ ) and the mass change for the sample was recorded.

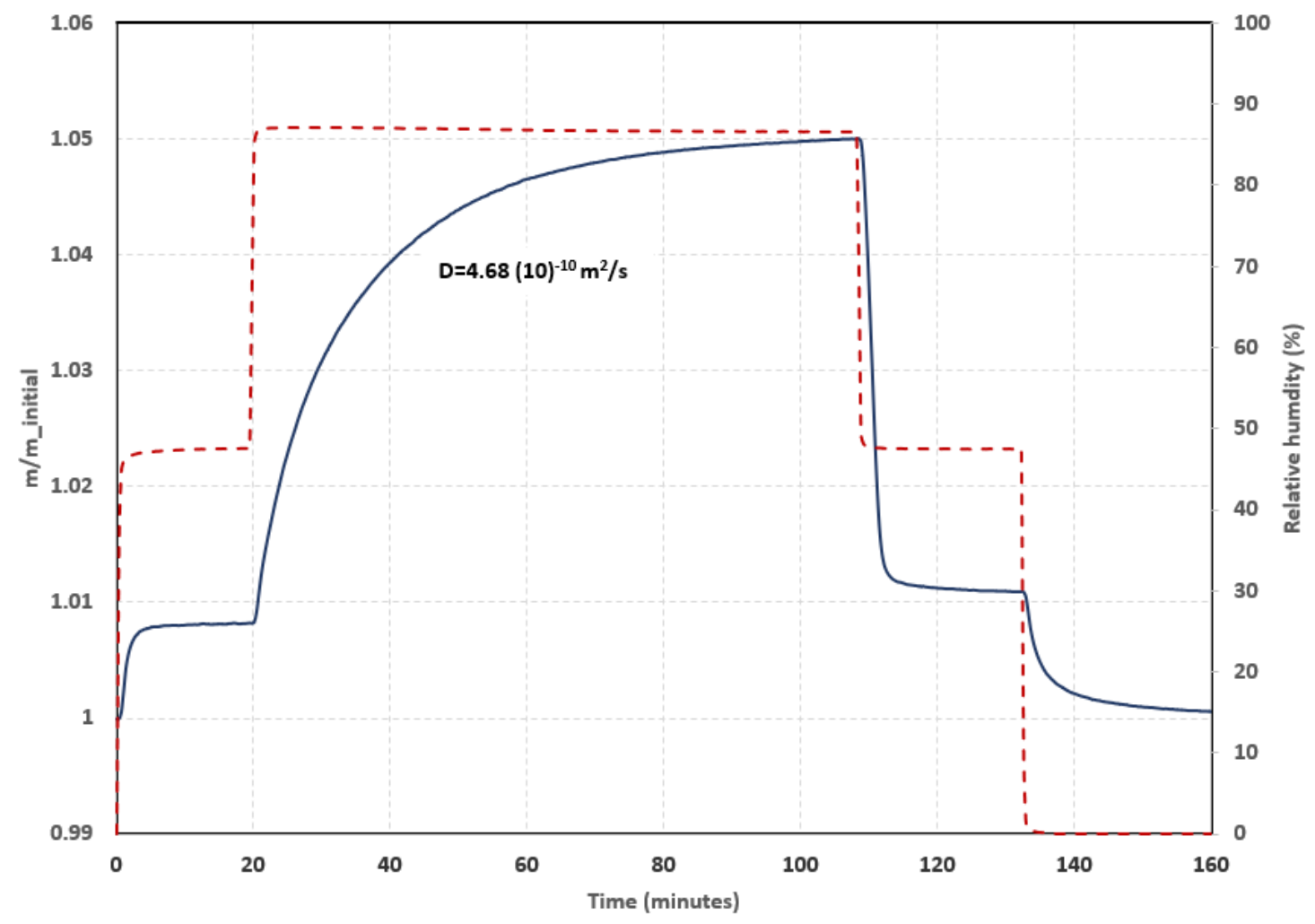

Figure 1. Moisture adsorption/desorption behavior of the AAO sample

The following important aspects have been observed through experiments:

i. The desorption rate for the sample is higher compared to the adsorption rate ( $45 \% \mathrm{RH}$ to $85 \% \mathrm{RH}$ compared to $85 \% \mathrm{RH}$ to $45 \% \mathrm{RH})$.

ii. The sample can absorb around $5.0 \%$ of the dry mass under extreme conditions $(85 \% \mathrm{RH})$. 
iii. There is a minor hysteresis $(0.275 \%)$ in adsorption and desorption processes.

\subsubsection{Mass diffusion model equations and domain}

The kinetic data was used to determine the mass diffusivity of the material using the mass diffusion model. The concentration, distance, diffusivity and time are represented by $\rho, x, D$ and $t$ respectively. It was assumed that the initial concentration of moisture (after the drying process) is zero and, fixed concentration and adiabatic wall conditions have been assumed at the surface and center of the sample.

Concentration equation:

$$
\frac{\partial \rho}{\partial t}=D\left(\frac{\partial^{2} \rho}{\partial x^{2}}\right)
$$

Initial condition:

$$
\rho(x, t=0)=0
$$

Boundary conditions:

$$
\begin{gathered}
\rho(x=L / 2, t)=\rho_{\infty} \\
\frac{\partial \rho}{\partial r}(x=0, t)=0
\end{gathered}
$$

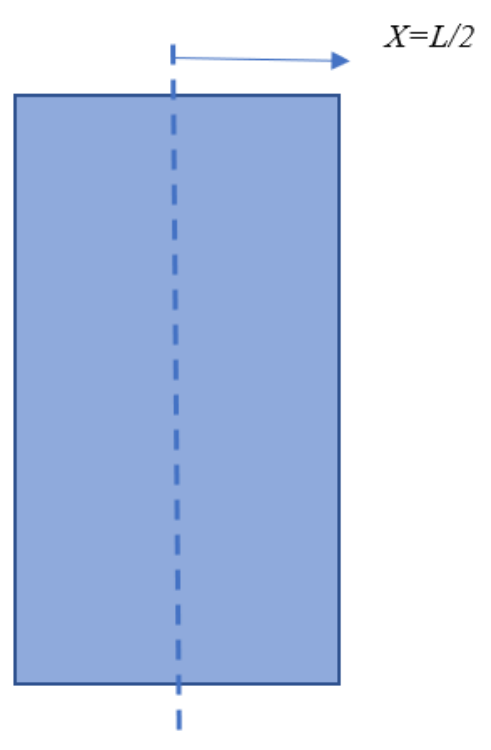

Figure 2. Mass diffusion model domain 


\subsection{LABORATORY-DERIVED FILM}

A porous alumina film was prepared by the method described by Leenaars et al [1]. First a sol was prepared, and an aliquot of the sol was dried under controlled humidity in a polystyrene dish to yield a xerogel. Heating increases the pore size and Anderson et al [2] found a pore size of approximately $4 \mathrm{~nm}$ when heated to $500^{\circ} \mathrm{C}$. As we desired a slightly larger pore size (approximately $5 \mathrm{~nm}$ ), the dried xerogel was heat treated in air at $600^{\circ} \mathrm{C}$ in air for one hour. Typical porosities for heat treated xerogels range from about 30 to $50 \%$ [3].

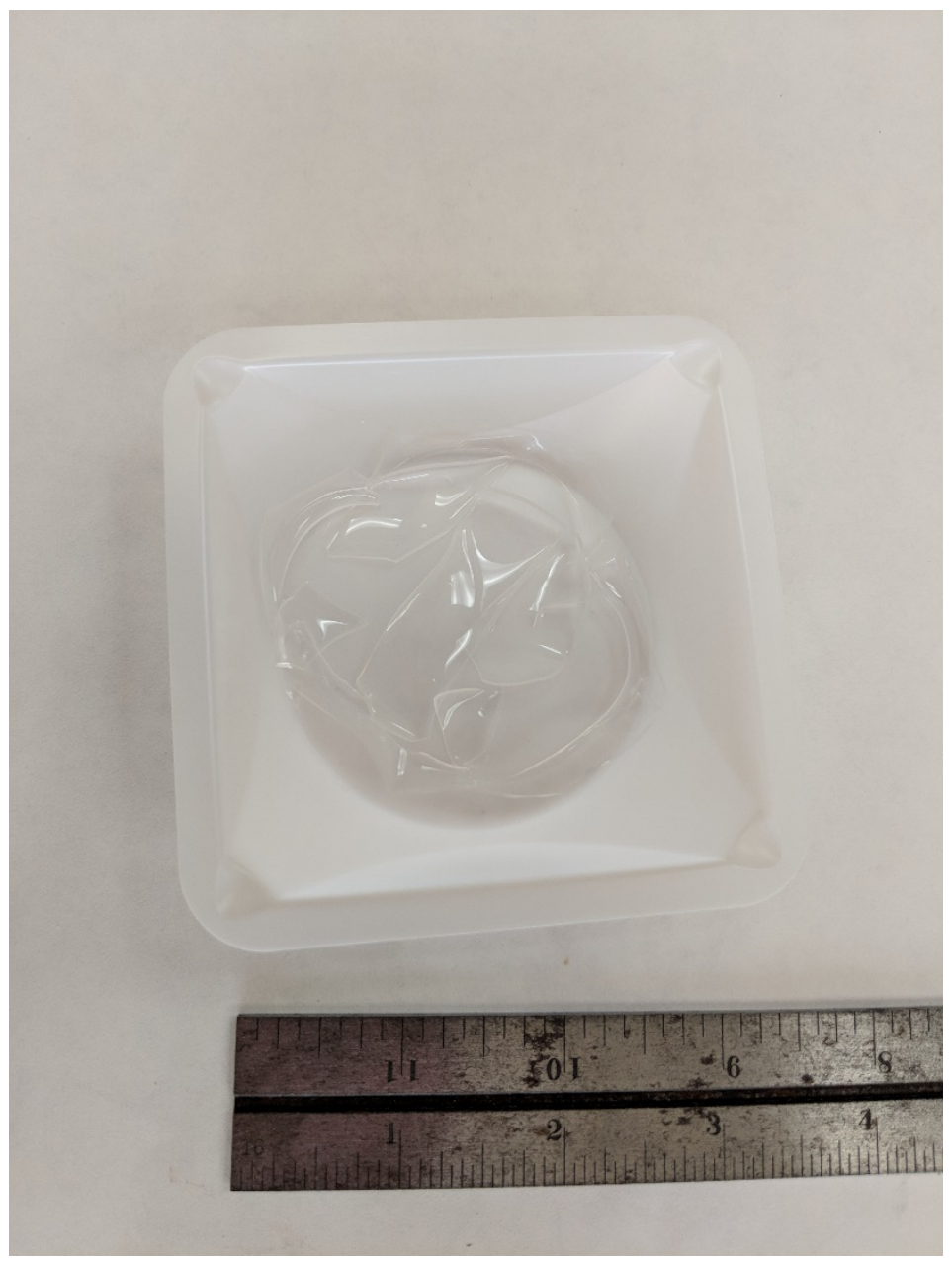

Figure 3. Photograph of dried xerogel

\subsection{REFERENCES}

[1] Leenaars. A.F.M., and Burggraaf, A.J., The Preparation and Characterization of Alumina Membranes with Ultrafine Pores, J. Colloid and Interface Science, Vol 105, 1, pp. 27-40, 1985.

[2] Anderson, M.A., Gieselmann, M.J., and Xu, Q., Titania and Alumina Ceramic Membranes, J. Memb. Sci, 39, pp243-258, 1988.

[3] Yoldas, B.E., Alumina gels that form porous transparent Al2O3, J. Mat. Sci., 10, pp 1856-1860, 1975. 


\section{ULTRASONIC TRANSDUCER MODELING}

Research on atomization of water droplets has unanimously confirmed the dependence of drop bursting on a critical acceleration value related to properties of the droplet. Therefore, the performance of the ultrasonic transducer is entirely dependent on the plate-substrate reaching large magnitudes of acceleration. A multi-physics model of the transducer is capable of evaluating geometry and material changes to the transducer while measuring their effect on acceleration. For this purpose, a finite element method (FEM) model of the transducer was created using COMSOL Multiphysics, a commercially available simulation software. For verification of the software's accuracy, an equivalent analytical model was developed for a particular arrangement of the transducer.

The approach for the analytical model was to consider the harmonic forcing of the PZT ring as a harmonic base excitation of the plate (Figure 4). The stainless-steel substrate of the transducer has dimensions and displacements which allow for the assumption of classical plate theory. The symmetry of the transducer is also captured by assuming an axisymmetric response. Using principles of mechanical vibrations, an expression for the acceleration at any point on the transducer as a function of radial position and time was developed. A detailed derivation of this expression can be found in Dupuis et. al. 2018 SPIE (Appendix A).

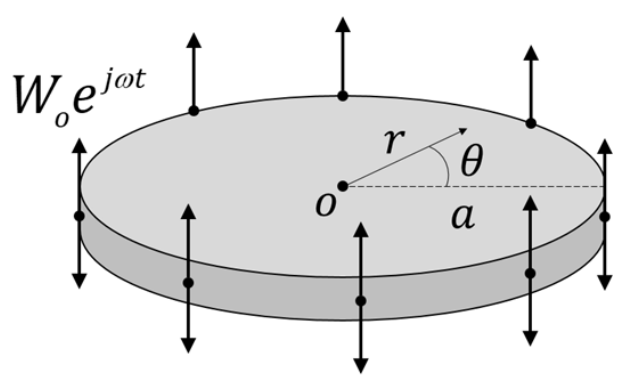

Figure 4. Thin plate undergoing harmonic base excitation about its circumference

Figure 5a shows the finite element model used to confirm the analytical plate model. For both models of the plate, the circumference is given a harmonic displacement in the thickness direction and is constrained from motion in all other directions. Figure $5 \mathrm{~b}$ is a more accurate model of the transducer, which incorporates the PZT rings. For this model, the forcing comes from the actuation of the PZT rings via an $\mathrm{AC}$ voltage source, rather than a prescribed base displacement.
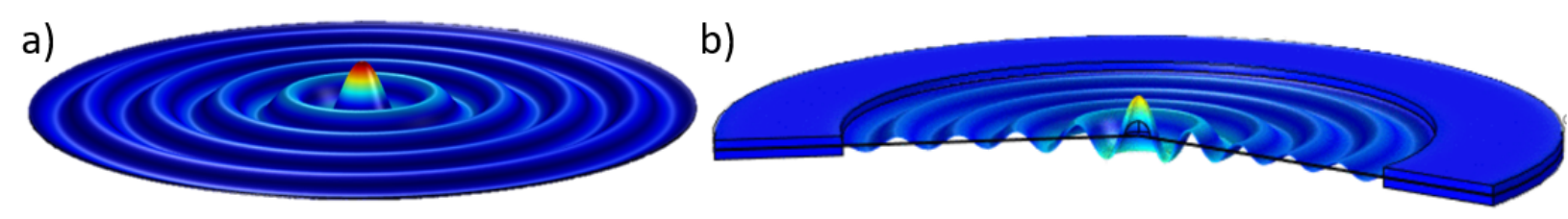

Figure 5. a) FEM plate model. b) FEM transducer model

A comparison of frequency-response-functions (FRF's) for the two plate models is given in Figure 6. It can be seen that the two solutions are nearly identical, which indicates the correct application of boundary conditions and forcing parameters for both models. The natural frequencies also match, indicating the assumption of an axisymmetric response was accurate. 


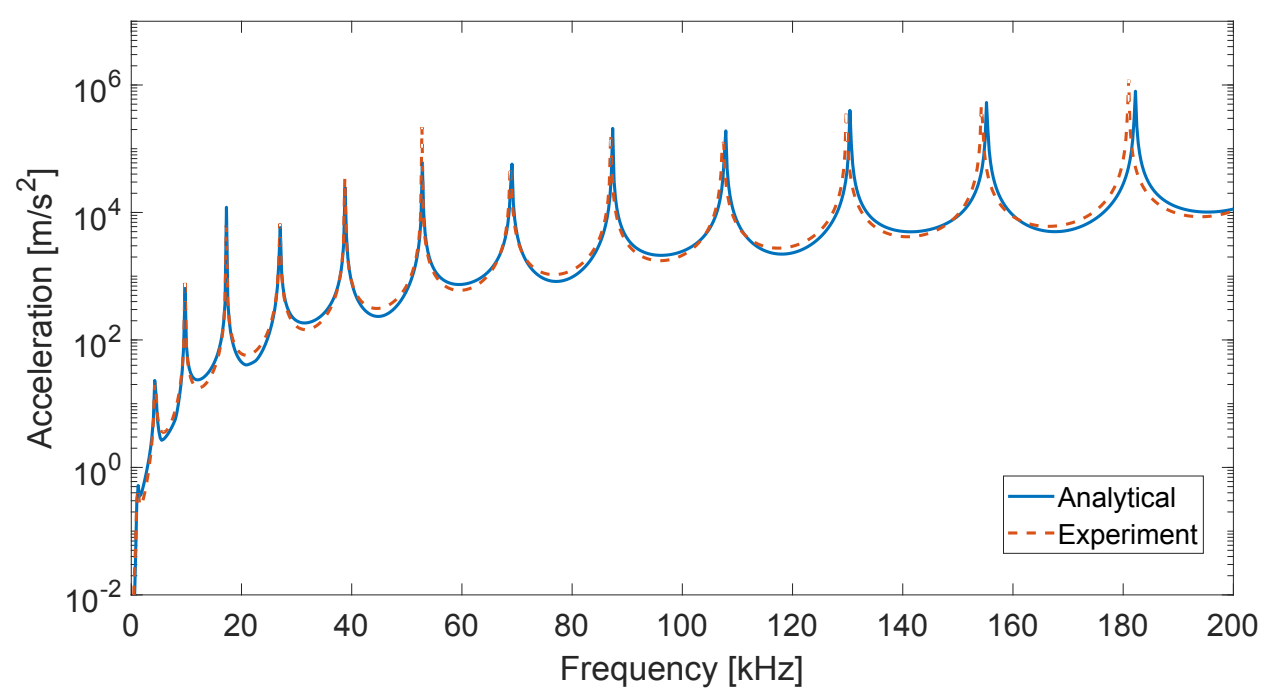

Figure 6. Acceleration FRF for the analytical and finite element plate model

Now that we have confirmed the two plate models agreement, we would like to see if there is a substantial difference when the PZT rings are incorporated, and if these results agree with experimentally measured values from a transducer under similar boundary conditions. The experimental data was collected using a single-point laser Doppler vibrometer (LDV) (Figure 7). Figure 8 compares the acceleration FRF of the simulated transducer, the real transducer, and the analytical plate model. Also plotted, is the minimum acceleration needed to achieve atomization. While the incorporation of the PZT rings on the FEM model does have some effect on the natural frequencies, we can see there is still a very good agreement between experiment and simulation. It is also important to note that the location where the FRF's intersect the acceleration threshold, at approximately $105 \mathrm{kHz}$, is the exact location where atomization of a droplet was witnessed during experimentally. The transducer exhibits linear behavior for operating frequencies up to $110 \mathrm{kHz}$, but the response becomes chaotic after this range. Although the model does not accurately capture the response of the transducer above this frequency, it is outside of the manufacturer recommended operating condition and is not cause for concern.

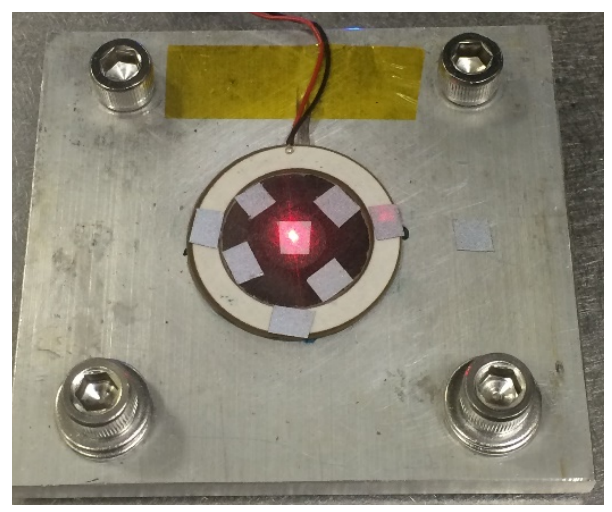

Figure 7. Mounted transducer with reflective tape for LDV measurements 


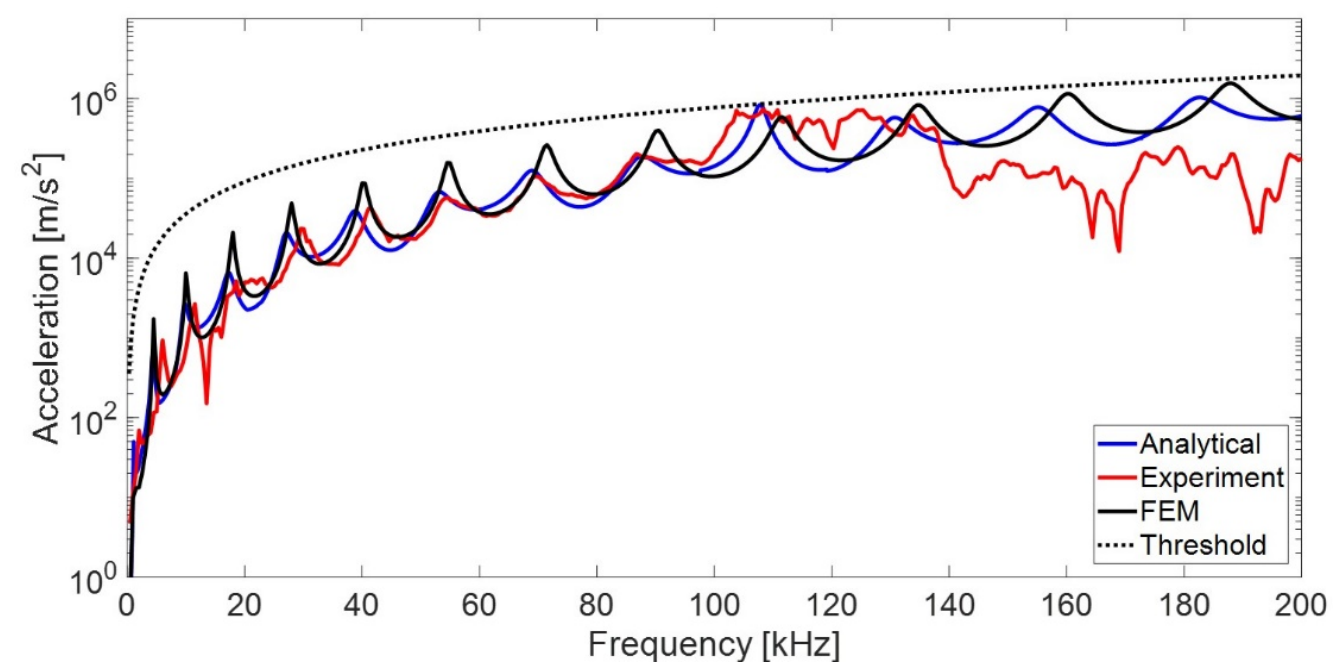

Figure 8. Acceleration FRF comparisons

A model of the transducer has been successfully created and from it the onset of atomization can be predicted. From this model, changes to the transducer such as dimensions and materials can be analyzed to produce the largest acceleration from the least amount of input power. This model will help to develop the ultrasonic dehumidifier as well as analyze its performance. Future designs of the transducer can create an atomizer specific to the needs of the dehumidifier. 


\section{APPENDIX A. MULTIPHYSICS MODELING CONFERENCE PUBLICATION}




\title{
APPENDIX A. MULTIPHYSICS MODELING OF MESH PIEZOELECTRIC TRANSDUCERS
}

The following paper was presented at the International Society for Optics and Photonics (SPIE) conference on Smart Structures and Nondestructive Evaluation, in Denver, CO, March 2018.

\section{Multiphysics modeling of mesh piezoelectric atomizers}

\author{
Eric Dupuis*a, Ayyoub M. Momen ${ }^{\mathrm{b}}$, Viral K. Patel ${ }^{\mathrm{b}}$, and Shima Shahab \\ ${ }^{a}$ Department of Biomedical Engineering and Mechanics, Virginia Tech, Blacksburg, VA USA ${ }^{\mathrm{b}}$ Building \\ Equipment Research, Energy and Transportation Science Division, Oak Ridge National Laboratory, Oak \\ Ridge, TN USA
}

\begin{abstract}
An ultrasonic clothes dryer was developed by researchers at Oak Ridge National Laboratory based on a novel approach of using high-frequency mechanical vibration instead of heat to extract moisture as a cold mist. This technology is based on direct mechanical coupling between mesh piezoelectric (PZT) transducers and wet fabric. The vibration introduces sufficient momentum to the droplets trapped in the fabric pores to atomize them and leave the garment in a cold state. In the vibrating transducer, deformation followed by the effects of boundary layer acoustic streaming results in ejection of the atomized droplets. The research presented bridges the vibration of a PZT mesh transducer to the induced acoustic field and to capillary-wave theory. Mathematical modeling studies free and forced vibrations of a mesh-like PZT structure, using the structural parameters identified by actuation testing in several case studies. Computational fluid-structure interaction modeling is performed to couple the vibrations of a PZT transducer with an in-contact droplet. The results obtained are used to investigate (1) the transverse deformation of the vibrating mesh transducer in contact with a droplet, (2) the resultant boundary layer acoustic streaming in the fluid surrounding the vibrating surface, and (3) the droplet deformation and fluid ejection. The physics of atomization are linked to the level of the near-wall droplet vibrations induced by the surface deformation of the transducer. Then the surface deformation is linked to the properties of the PZT mesh transducer and input actuation frequency and power.
\end{abstract}

Keywords: Piezoelectric, transducer, ultrasonic dryer, vibrations, plate, atomizer, drop bursting

\section{INTRODUCTION}

\subsection{Ultrasonic dryer: working principles}

There are two major theories for the mechanics governing the atomization of a liquid into droplets: capillary wave theory and cavitation theory ${ }^{1}$. Capillary wave theory argues that droplet formation is due to high-intensity surface waves propagating at the liquid-vapor interface which become unstable and rupture, leading to the ejection of droplets from a liquid body. Cavitation theory argues that the implosion of cavitation bubbles and the resulting shock wave overcomes surface tension to eject droplets at high velocities. Recent studies have used both explanations to successfully predict the size of ejected droplets as well as the acceleration frequency and amplitude necessary for ejection ${ }^{2-5}$.

Vertical oscillations of a contained liquid, called "Faraday excitation", result in the formation of standing waves on the liquid surface. ${ }^{2-5}$. At increasing amplitudes and frequencies of oscillation, wave peaks become extended, and form a neck that connect small secondary droplets to the bulk liquid. When the oscillation reaches an acceleration threshold, the droplet momentum is sufficient to break the surface tension of the neck and enable the droplets to break away from the liquid ${ }^{5}$. High-frequency oscillations result in smaller wave lengths with enough surface tension to resist the momentum of the secondary droplet. When these oscillations are present, cavitation theory dominates and smaller droplets with larger velocities are expelled. The rapid ejection of an entire liquid body in many secondary droplets is called "drop bursting". ${ }^{2}$ 
A model predicting drop bursting as a result of Faraday excitation will be explored in future publications. It is beneficial to control droplet size, as the pores in fabrics vary in spacing from one material to another. To be fully ejected, the liquid suspended in the fabric must be atomized into droplets smaller than the area between woven threads. The ability to control the energy expended in a drying cycle based on the demands of the material will increase the overall efficiency of residential drying. This study builds the foundation for prediction of drop bursting by analyzing the diaphragm responsible for the application of Faraday excitation in the ultrasonic dryer.

*edupuis@vt.edu; phone 1 617-312-4874

\subsection{Ultrasonic dryer: design}

The ultrasonic dryer created at Oak Ridge National Laboratory (ORNL) used the framework of a modified electricresistance tumble dryer. ${ }^{6}$ Sections of the drum wall were cut out and replaced with a circuit board containing an array of piezoelectric (PZT) transducers (Figure 1). The rotation of the drum causes different areas of wet fabrics to come into contact with the area of a PZT transducer at different times; over the duration of a drying cycle, the entire area of the clothing experiences the mechanical vibrations responsible for atomization.

The current prototype uses 120 PZT transducers, each consisting of two PZT-5A (PZT) rings adhered to the upper and lower surfaces of a thin circular plate made of stainless steel (Figure 2). An area at the center of the plate has an array of holes. These facilitate the movement of water from inside the rotating drum to its outer region, where the atomized water is either ventilated from the dryer or allowed to condense and flow away.

This study analyzes the vibrations of the ultrasonic transducer stainless steel plate resulting from the deformation imposed by actuation of the PZT rings. A frequency-response function (FRF) was developed both analytically and via the finite element method (FEM) using the commercial software COMSOL Multiphysics. Because of the dominance of acceleration over drop bursting, the focus is on predicting the maximum acceleration of the vibrating plate. The analytical model will be used in future work to optimize the transducer design to facilitate efficient atomization.
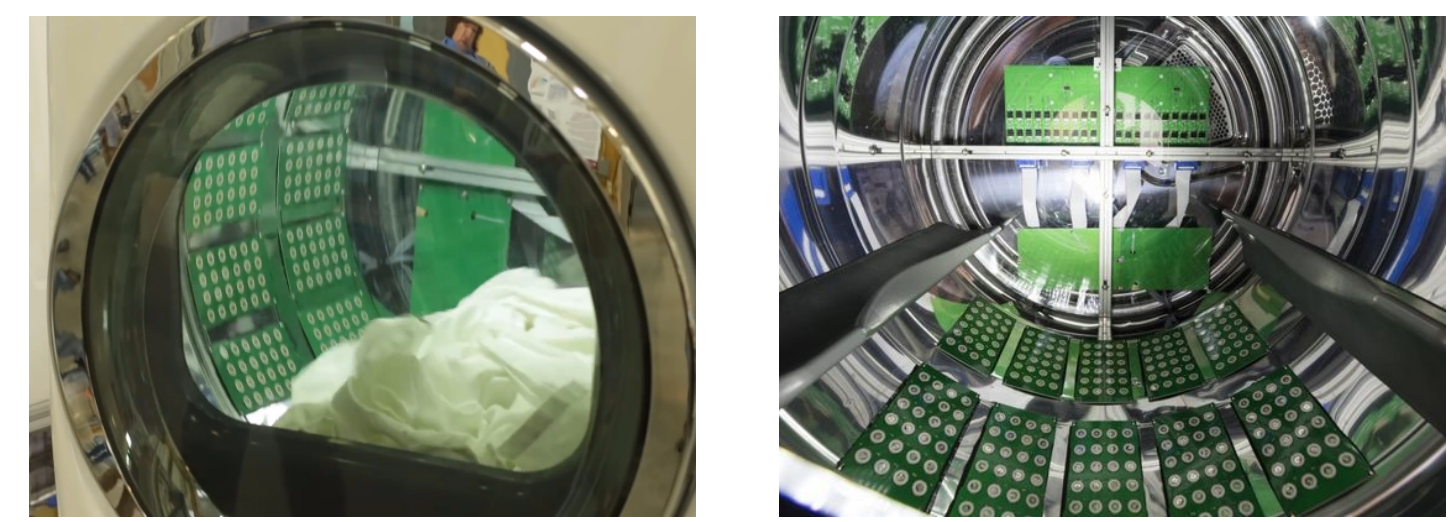

Figure 1. Ultrasonic prototype dryer with arrays of transducers on circuit boards attached to the inside of a tumbledryer drum. Photographs courtesy of ORNL. 


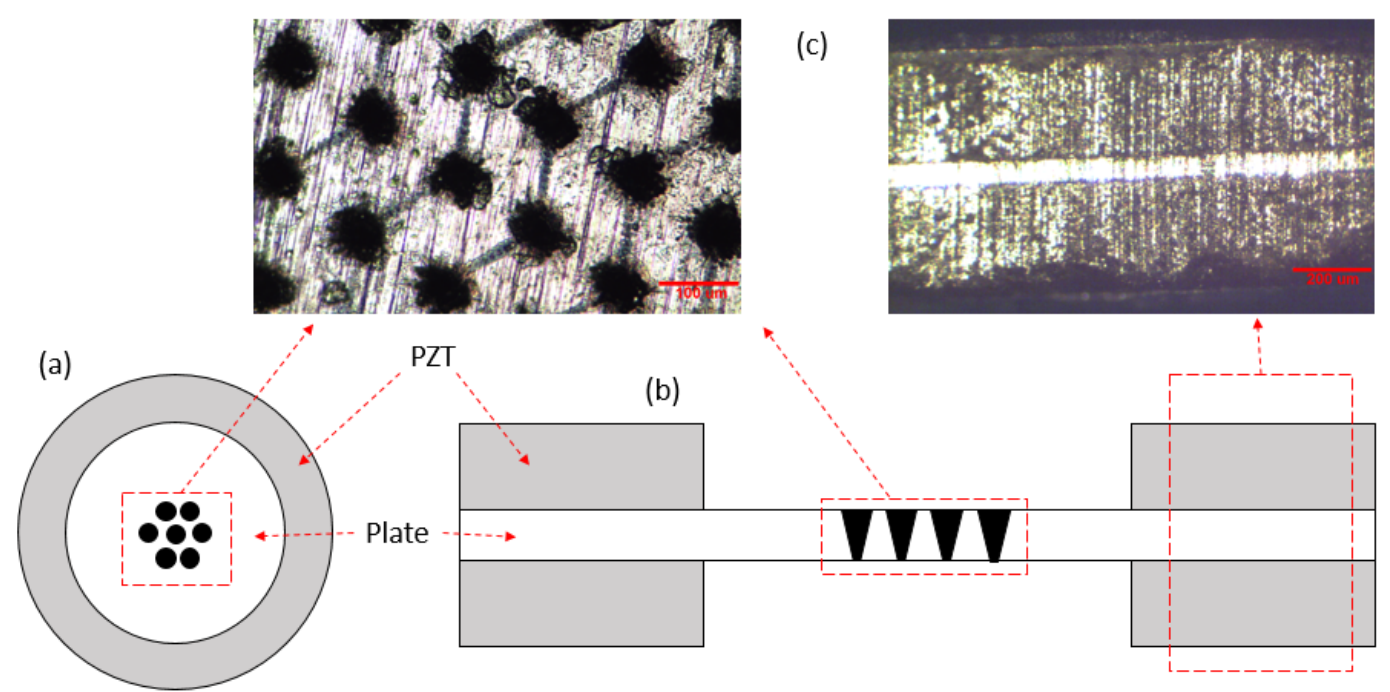

Figure 2. (a) Top view of the transducer, (b) A cross section of the transducer and (c) microscopic images of its geometry.

\section{THEORY}

\subsection{Problem statement}

The PZT transducer consists of a stainless steel substrate with two PZT rings adhered to its upper and lower surfaces (see Figure 2). The PZT and plate have an outer diameter of $30 \mathrm{~mm}$. The inner diameter of the PZT ring is $21 \mathrm{~mm}$, and the thicknesses of the PZT and plate are $0.32 \mathrm{~mm}$ and $0.05 \mathrm{~mm}$, respectively. Each PZT layer has its negative terminal adhered to the stainless plate, and both are poled away from the plate. When actuated by an $\mathrm{AC}$ voltage source, the PZT's harmonic deformation imposes alternating compressive and tensile forces on the substrate as a result of thickness-mode excitation. The energy from these forces results in transverse vibrations dependent upon the frequency and amplitude of the excitation.

The transducers' working principle can be decoupled into two parts: (1) the PZT vibration under harmonic actuation and (2) the plate deformation due to the PZT actuation. This study focuses on the latter aspect of the system. The decoupled problem considers the domain of the plate to be the area free from contact with the PZT (within the inner radius of the PZT). A free vibration study (eigenvalue analysis) was conducted to calculate the natural frequencies and mode shapes of the plate. Results of the free vibration study for both the analytical and FEM cases are compared in Table 1.

Following the free vibration study, the forced vibration of the plate as a result of a uniform sinusoidal excitation about its circumference was modeled. It can be seen from the cross section image of the transducer (see Figure 2) that the outer portion of the plate is entirely adhered between the PZT rings, which operate in the 33 mode of piezoelectricity with a fundamental resonance frequency above the human audible frequency range. This portion of the plate has no relative displacement, as it is constrained above and below by the PZT. Thus, the uniform sinusoidal excitation is imposed on the plate at $r=a$. The boundary conditions at this location were considered to be clamped.

Table 1. Plate properties and dimensions.

\begin{tabular}{l|llllll} 
Parameter & Radius & Thickness & Density & $\begin{array}{l}\text { Flexural } \\
\text { Rigidity }\end{array}$ & $\begin{array}{c}\text { Young's } \\
\text { Modulus }\end{array}$ & $\begin{array}{l}\text { Poisson's } \\
\text { Ratio }\end{array}$ \\
\cline { 2 - 6 } Symbol & $a$ & $h$ & $\rho$ & $D$ & $E$ & $v$ \\
Value & 10.5 & 0.05 & 8,000 & $\frac{E h^{3}}{12\left(1-v^{2}\right)}$ & 200 & 0.30 \\
& {$[\mathrm{~mm}]$} & {$[\mathrm{mm}]$} & {$\left[\mathrm{kg} \cdot \mathrm{m}^{-3}\right]$} & &
\end{tabular}




\subsection{Free vibration analysis}

The boundary value problem of the plate shown in Figure 3 in free vibration was solved for the mode shapes and natural frequencies of the plate. The equation of motion (EOM) for the undamped free vibration of the plate can be expressed as ${ }^{7}$ :

$$
D \nabla^{4} w(r, \theta, t)+\rho h \frac{\partial^{2} w(r, \theta, t)}{\partial t^{2}}=0,
$$

where $D, \rho, h$ are given by Table $1, r$ and $\theta$ are polar coordinates of the plates upper surface, and $w$ is the displacement of the surface from equilibrium. Using separation of variables, we can express the space function of the EOM as:

$$
\nabla^{4} \phi(r, \theta)-\lambda^{4} \phi(r, \theta)=0
$$

where the Eigenvalue $\lambda$ is expressed as

$$
\lambda^{4}=\frac{\rho h \omega^{2}}{D}
$$

with $\omega$ representing the natural frequency. The solution to Eq. (2.2) is the generalized shape function?:

$$
\phi(r, \theta)=\left[C_{m}^{1} J_{m}(\lambda r)+C_{m}^{2} Y_{m}(\lambda r)+C_{m}^{3} I_{m}(\lambda r)+C_{m}^{4} K_{m}(\lambda r)\right]\left(A_{m} \cos (m \theta)+B_{m} \sin (m \theta)\right),
$$

where $J_{m}$ and $Y_{m}$ are Bessel functions of order $m$ of the first and second kind, respectively. $I_{m}$ and $K_{m}$ are modified Bessel functions of order $m$ of the first and second kind, respectively. $C_{m}, A_{m}$, and $B_{m}$ are unknown constants. The modified Bessel functions have infinite value at $r=0$, therefore the constants associated with them must be zero for the plate response to be finite.

The circumference of the plate has clamped boundary conditions; therefore,

$$
w_{r e l}(a, \theta, t)=0,\left.\quad \frac{\partial w_{r e l}(r, \theta, t)}{\partial r}\right|_{r=a}=0 .
$$

Applying Eq. (2.5) to Eq. (2.4) and using known relations of the Bessel functions ${ }^{7}$, we find the characteristic equation to be

$$
J_{m}\left(\lambda_{n} a\right) I_{m-1}\left(\lambda_{n} a\right)-J_{m}\left(\lambda_{n} a\right) I_{m-1}\left(\lambda_{n} a\right)=0 .
$$

The roots of Eq. (2.6), $\lambda_{n} a$, are the Eigenvalues multiplied by the plate radius. Using Eq. (2.3) with the obtained Eigenvalues, we find the natural frequencies for the free vibration of a plate clamped about its circumference. The mode shapes of the plate are found by substituting the Eigenvalues into Eq. (2.4).
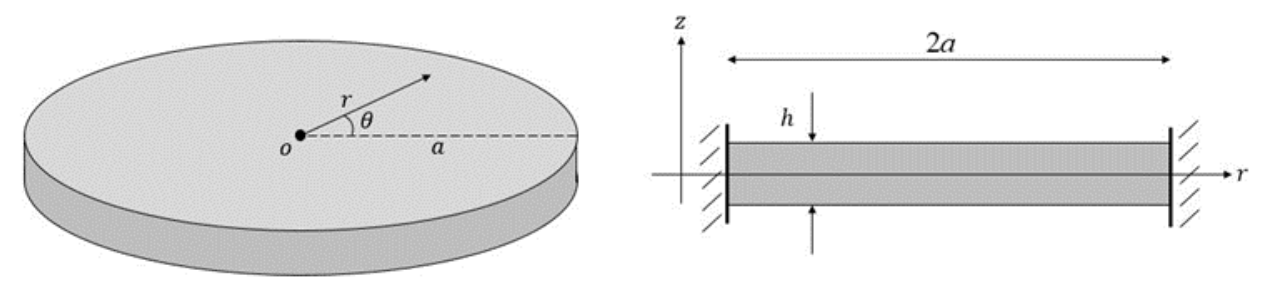

Figure 3. The circular plate geometry and dimensions.

\subsection{Forced vibration analysis: Axial base excitation at the circumference}

The damped version of the plate in Eq. (2.1) was studied, with the clamped circumference excited by a harmonic displacement. For this study, the plate vibrations were assumed to be axisymmetric; that is, they do not vary with $\theta$. The damped EOM of the plate is 


$$
D \nabla^{4} w(r, t)+c_{s} \frac{\partial}{\partial t} \nabla^{4} w(r, t)+c_{a} \frac{\partial w(r, t)}{\partial t}+\rho h \frac{\partial^{2} w(r, t)}{\partial t^{2}}=0
$$

where $c_{S}$ and $c_{a}$ are the strain-rate and viscous air damping coefficient, respectively. The plate displacement can be expressed as the sum of motions of the base excitation, and the resulting relative displacement:

$$
w(r, t)=w_{b}(r, t)+w_{r e l}(r, t) .
$$

The base excitation can be expressed as the sum of a displacement, $g(t)$, and a rotation, $h(t)$, which are multiplied by an influence function, $\delta$, that is dependent upon the boundary conditions ${ }^{8}$ :

$$
w_{b}(r, t)=\delta_{1}(r) g(t)+\delta_{2}(r) h(t)
$$

Applying Eq. (2.8) to Eq. (2.7), we find the damped EOM for the base excitation of a plate:

$$
D \nabla^{4} w_{r e l}(r, t)+c_{s} \frac{\partial}{\partial t} \nabla^{4} w_{r e l}(r, t)+c_{a} \frac{\partial w_{r e l}(r, t)}{\partial t}+\rho h \frac{\partial^{2} w_{r e l}(r, t)}{\partial t^{2}}=-c_{a} \frac{\partial w_{b}(r, t)}{\partial t}-\rho h \frac{\partial^{2} w_{b}(r, t)}{\partial t^{2}} .
$$

The solution of Eq. (2.10) can be expressed as a convergent series of shape and time functions using the method of separation of variables:

$$
w_{r e l}(r, t)=\sum_{n=1}^{\infty} \phi_{n}(r) \eta_{n}(t)
$$

The shape function of the solution to the damped EOM is the same as that for the undamped free vibration case, where $E_{n}$ in Eq. (2.14) is the modal amplitude constant, found by using the orthogonality conditions (Eq. [2.13]) and boundary conditions (Eq. [2.5]). The modal amplitude constant is expressed as ${ }^{9}$

$$
E_{n}=\sqrt{\frac{\delta_{m n}}{2 \pi \rho h \int_{0}^{a} r\left[J_{0}\left(\lambda_{m} r\right) I_{0}\left(\lambda_{m} a\right)-J_{0}\left(\lambda_{m} a\right) I_{0}\left(\lambda_{m} r\right)\right]\left[J_{0}\left(\lambda_{n} r\right) I_{0}\left(\lambda_{n} a\right)-J_{0}\left(\lambda_{n} a\right) I_{0}\left(\lambda_{n} r\right)\right] d r}},
$$

where $\delta_{m n}$ is the Kronecker delta. The mass normalized shape functions satisfy the orthogonality conditions ${ }^{8,9}$ :

$$
\int_{0}^{a} 2 \pi r \rho h \phi_{m}(r) \phi_{n}(r) d r=\delta_{m n}, \quad \int_{0}^{a} 2 \pi r \phi_{s}(r) D \nabla^{4} \phi_{n}(r) d r=\omega_{n}^{2} \delta_{m n} .
$$

The mass normalized shape function is

$$
\phi_{n}(r)=E_{n}\left[J_{0}\left(\lambda_{n} r\right) I_{0}\left(\lambda_{n} a\right)-J_{0}\left(\lambda_{n} a\right) I_{0}\left(\lambda_{n} r\right)\right] .
$$

Using Eqs. (2.5), (2.10), and (2.14), the partial differential EOM can be reduced to an infinite set of ordinary differential equations of the form ${ }^{8}$

$$
\frac{\partial^{2} \eta_{n}(t)}{\partial t^{2}}+2 \zeta_{n} \omega_{n} \frac{\partial \eta_{n}(t)}{\partial t}+\omega_{n}^{2} \eta_{n}(t)=f_{n}(t)
$$

where

$$
2 \zeta_{n} \omega_{n}=\frac{c_{s} \omega_{n}^{2}}{D}+\frac{c_{a}}{\rho h}
$$

Therefore the damping ratio $\zeta_{n}$ includes the strain-rate damping and viscous damping effects, expressed as $\zeta_{n}=\zeta_{n}^{s}+\zeta_{n}^{a}$, where the strain-rate and viscous damping are $\zeta_{n}^{s}=\frac{c_{s} \omega_{n}}{2 D}$ and $\zeta_{n}^{a}=\frac{c_{a}}{2 \rho h \omega_{n}}$, respectively. In Eq. (2.15) the modal forcing function $f_{n}(t)$ can be expressed as the sum of inertia and damping related terms by 


$$
f_{n}(t)=f_{n}^{m}(t)+f_{n}^{c}(t)
$$

Here, the inertia-related and damping-related excitation terms are given by the following expressions ${ }^{8}$ :

$$
f_{n}^{m}(t)=-\rho h\left(\gamma_{n}^{w} \frac{\partial^{2} g(t)}{\partial t^{2}}+\gamma_{n}^{\theta} \frac{\partial^{2} h(t)}{\partial t^{2}}\right), \quad f_{n}^{c}(t)=-c_{a}\left(\gamma_{n}^{w} \frac{\partial g(t)}{\partial t}+\gamma_{n}^{\theta} \frac{\partial h(t)}{\partial t}\right)
$$

where

$$
\gamma_{n}^{w}=\int_{0}^{a} 2 \pi r \phi_{n}(r) d r, \quad \gamma_{n}^{\theta}=\int_{0}^{a} 2 \pi r^{2} \phi_{n}(x) d r
$$

Therefore the modal forcing function is

$$
f_{n}(t)=-2 \pi \rho h\left[\frac{\partial^{2} g(t)}{\partial t^{2}} \int_{0}^{a} r \phi_{n}(r) d r+\frac{\partial^{2} h(t)}{\partial t^{2}} \int_{0}^{a} r^{2} \phi_{n}(x) d r\right]-2 \pi c_{a}\left[\frac{\partial g(t)}{\partial t} \int_{0}^{a} r \phi_{n}(r) d r+\frac{\partial h(t)}{\partial t} \int_{0}^{a} r^{2} \phi_{n}(x) d r\right]
$$

For a plate under harmonic base excitation with no rotation, and neglecting viscous air damping, only the first term on the right-hand side of Eq. (2.20) remains; therefore, it is expressed as

$$
f_{n}(t)=2 \pi \rho h \omega^{2} W_{o} e^{j \omega t} \int_{0}^{a} r \phi_{n}(r) d r
$$

The displacement function $g(t)$ is assumed to be of the form $W_{o} e^{j \omega t}$, where $W_{o}$ is the amplitude of base excitation. We assume the time function from Eq. (2.11) is of the form:

$$
\eta_{n}(t)=A_{n} e^{j \omega t}
$$

where $A_{n}$ is an amplitude constant for mode $n$. Substituting Eq. (2.22) into Eq. (2.15), we find

$$
-\omega^{2} A_{n} e^{j \omega t}+2 j \zeta_{n} \omega_{n} \omega A_{n} e^{j \omega t}+\omega_{n}^{2} A_{n} e^{j \omega t}=f_{n}(t) .
$$

Solving Eq. (2.23) for $A_{n}$ yields

$$
A_{n}=\frac{f_{n}(t)}{\left(\omega_{n}^{2}-\omega^{2}+2 j \zeta_{n} \omega_{n} \omega\right) e^{j \omega t}}
$$

substituting Eq. (2.21) into Eq. (2.24) and cancelling terms, Eq. (2.24) becomes

$$
A_{n}=\frac{2 \pi \rho h \omega^{2} W_{o}^{a} r \phi_{0}(r) d r}{\omega_{n}^{2}-\omega^{2}+2 j \zeta_{n} \omega_{n} \omega}
$$

Considering the time function of Eq. (2.22) with the amplitude constant expressed as Eq. (2.24), and applying the result to Eq. (2.11), we find the expression for the relative displacement of the plate to be

$$
w_{r e l}(r, t)=\sum_{n=1}^{\infty} \phi_{n}(r) \frac{2 \pi \rho h \omega^{2} W_{o} \int_{0}^{a} r \phi_{n}(r) d r}{\omega_{n}^{2}-\omega^{2}+2 j \zeta_{n} \omega_{n} \omega} e^{j \omega t} .
$$

Taking the derivative of Eq. (2.26) twice with respect to time, we find the acceleration of a point on the plate surface. When a liquid comes into contact with the transducer, this acceleration, previously denoted as Faraday excitation, is responsible for atomization. 


\section{RESULTS AND DISCUSSION}

\subsection{Forced vibration analysis of a fully clamped plate}

A comparison of the analytical and FEM solution can be seen in Table 2 and Figure 4 . The FEM solution was computed using the structural mechanics module of COMSOL. Table 2 shows the natural frequencies calculated from the eigenvalue analysis for both models. These values were nearly identical, and the mode shapes were also found to match accordingly. This calculation validated the application of boundary conditions in the FEM. A mesh convergence study was performed on the first modal frequency, which led to choosing a mesh element size of $1 / 8 \mathrm{~mm}$, as well as a cubic function, as the assumed solution for the elements.

Table 2. Axisymmetric natural frequency comparison of the analytical and FEM free plate vibration study.

\begin{tabular}{l|llllllllll} 
Mode & 1 & 2 & 3 & 4 & 5 & 6 & 7 & 8 & 9 & 10 \\
\cline { 2 - 9 } Analytical [kHz] & 1.1121 & 4.3296 & 9.6998 & 17.2201 & 26.8892 & 38.7074 & 52.6742 & 68.7905 & 87.0553 & 107.4687 \\
FEM [kHz] & 1.1126 & 4.3307 & 9.8781 & 17.2156 & 26.8721 & 38.6651 & 52.5889 & 68.6367 & 86.9100 & 107.0734 \\
\% difference & 0.038 & 0.025 & 1.821 & 0.026 & 0.064 & 0.109 & 0.162 & 0.224 & 0.167 & 0.369
\end{tabular}

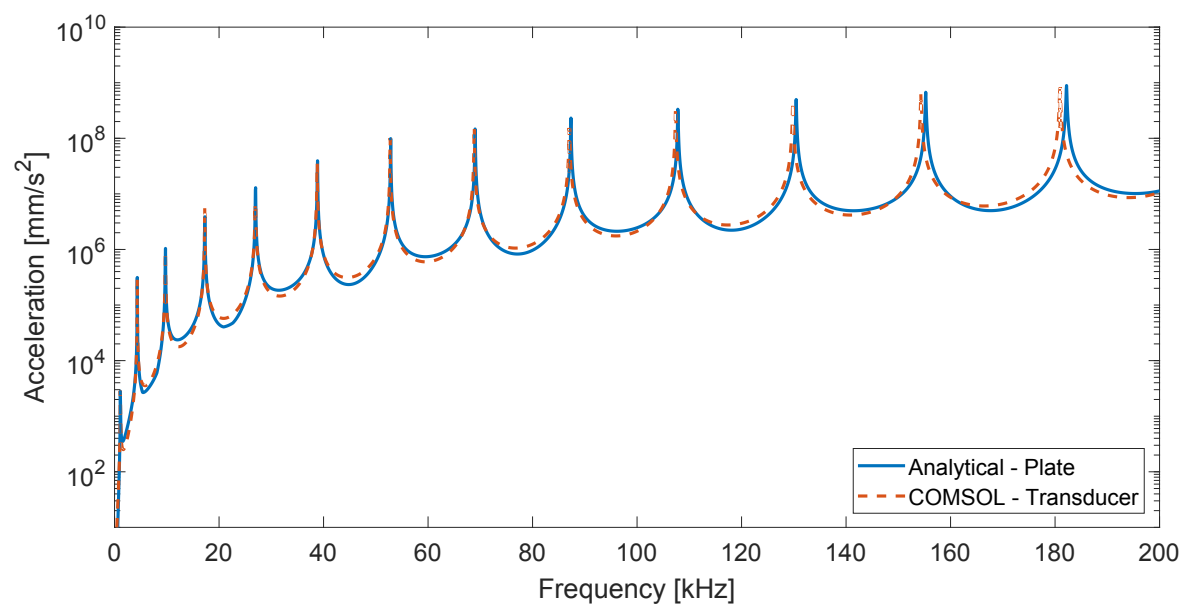

Figure 4. FRF comparison between analytical and COMSOL solutions.

To model the base excitation of the plate in COMSOL, the circumference of the plate was given a prescribed displacement in the thickness direction and was restricted from deforming radially. The amplitude of the displacement was chosen to be $1 \mu \mathrm{m}$, a value consistent with measured and simulated deformations of the PZT (Figure 6a). Since the analytical response was assumed to be axisymmetric, the same criteria were applied to the FEM model.

The analytical and FEM solutions for the forced vibration were nearly identical. This result indicates that the boundary conditions and assumptions used for the analytical expression were accurately imposed on the FEM. Future developments to increase the accuracy of the analytical model will consider the influence of the PZT on the coupled electromechanical problem. This will allow for the PZT deformation to be calculated analytically, rather than measured experimentally. Fluid loading effects will be included in future developments of the model as well.

\subsection{Experimental results and validation for an ultrasound atomizer}

A portion of the experimental setup can be seen in Figure 5a and a schematic of the entire experiment in Figure 5b. The transducer was bonded to a mounting plate using high-shear-strength epoxy via a vacuum bonding process detailed in a previous study. ${ }^{10}$ The mounting plate had a $7 / 8$ in. hole around which the transducer was centered. This allowed for the PZT to be rigidly connected while the plate was free to vibrate. A voltage signal was created with Signal Express and amplified to $50 \mathrm{~V}_{\mathrm{p}-\mathrm{p}}$ before the transducer was actuated. The response of the transducer was measured with a laser doppler vibrometer (LDV) (Polytec OFV 505) and collected with a data acquisition unit from National Instruments (model USB-6361). Reflective tape was placed on the transducer to increase the strength of the LDV signal. 


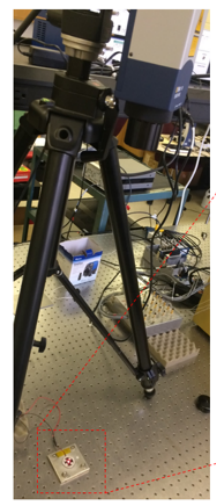

(a)

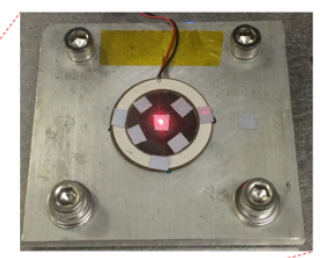

(b)

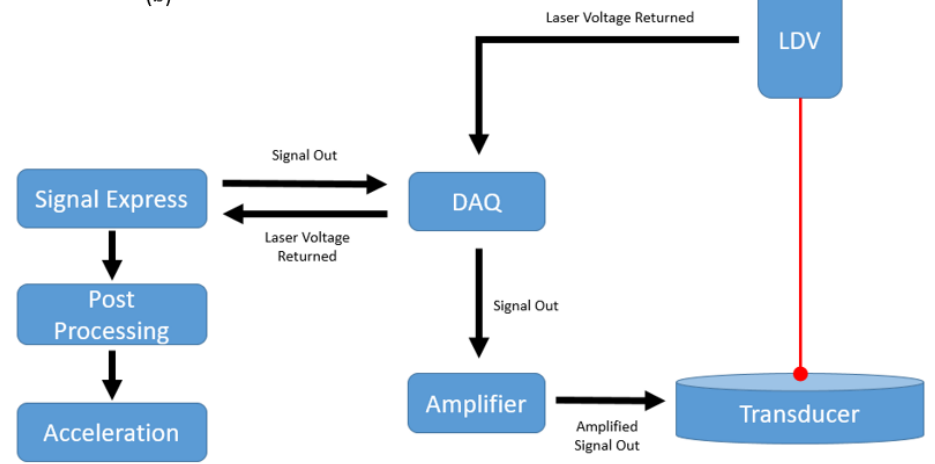

Figure 5. (a) Laser doppler vibrometer and piezoelectric transducer in testing. (b) Schematic of the experimental setup for measuring the transducer response to an applied voltage.

The complex electromechanical relationship of the PZT rings and plate was incorporated into the analytical model to increase the accuracy of the FRF. The midpoint of the PZT ring width was measured using the LDV (Figure 6a). This displacement then became the input amplitude, $W_{0}$, of Eq. (2.26).

For the FEM, this same task was carried out using the COMSOL Multiphysics capabilities. An electrostatic physics module was incorporated with the solid mechanics module. The PZT was added above and below the plate in accordance with the transducer geometry. Each ring received half of the $50 \mathrm{~V}_{\mathrm{p} \text {-p }}$ actuation voltage, and the bottom PZT surface was fixed from displacement, similar to the way the experimental transducer was adhered to a mounting plate. The FRF of these enhanced models is shown in comparison with the experimental values. Figure $6 \mathrm{~b}$ shows the maximum acceleration of the center of the transducer for both models, and the experimental measurements.
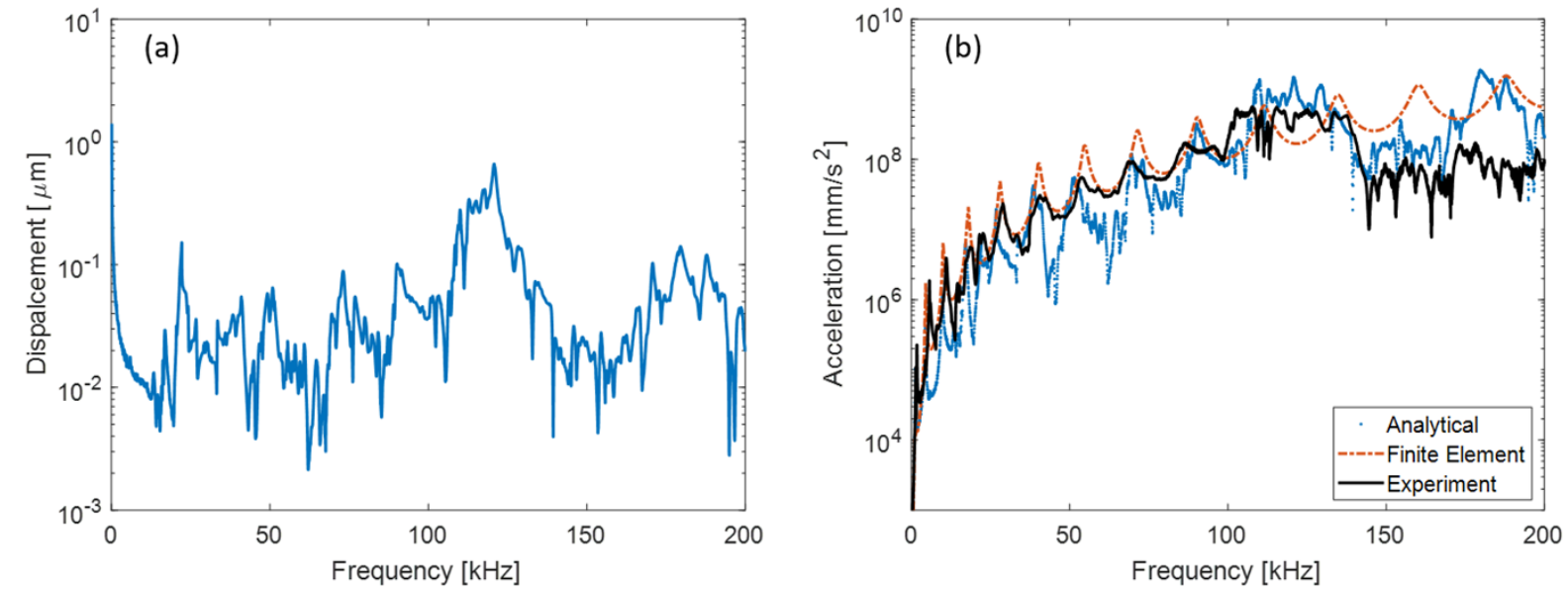

Figure 6. (a) Displacement amplitude $W_{0}$ measured at a midpoint of the PZT surface using a laser doppler vibrometer.

(b) Comparison of acceleration at the center of the transducer for the experimentally measured response, the analytical solution for the forced vibration of a plate, and an FEM simulation of the entire transducer.

Both models accurately predicted the acceleration of the transducer over a wide range of driving frequencies. The agreement between the modal peaks of the experimental and modeled cases indicates that the axisymmetric vibrations dominated the behavior of the plate. The FEM and analytical model are idealized cases of the transducer and do not capture sources of error such as manufacturing defects, misalignments, or nonlinearities. These are most prevalent at frequencies above $110 \mathrm{kHz}$. The steep drop-off in acceleration measured experimentally at this frequency indicated nonlinear behavior, which was captured by the analytical model only because experimental data were included. Note that neither model incorporated the microscopic holes in the plate. Because of the agreement of the FRF, it can be concluded that the holes had a negligible effect on the mass and stiffness of the plate. Future studies will analyze the acoustic-piezoelectric structure interaction. The pressure field propagating from the vibrating plate will have a role in 
atomization; the ability to quantify this force and relate it to the power input to the transducer will help create a fully coupled model..$^{11,12}$

\section{CONCLUSIONS}

The ultrasonic dryer uses the complex relationship between Faraday excitations and capillary wave theory to achieve drop bursting and subsequent ejection of secondary droplets from a fabric in order to dry clothing. The mechanics governing this process are far more energy efficient than those governing the operation of modern electric-resistance dryers. ${ }^{1}$ The ultrasonic transducer responsible for creating the Faraday excitation was analyzed experimentally, and an analytical and FEM model were created to predict the acceleration of its surface. The free and forced vibration studies of the analytical and COMSOL models matched exceptionally well and are the first step toward predicting drying rates. Future studies will use the models discussed in this paper, along with fluid-structure interactions, to predict drying rates for water suspended in a fabric. Optimization of the results will lead to transducer designs that increase the performance of the ultrasonic dryer.

\section{ACKNOWLEDGMENT}

This work was sponsored by the US Department of Energy Building Technologies Office under Contract No. BENEFIT 1632_1520 and NFE-17-06541 with UT-Battelle, LLC.

\section{REFERENCES}

[1] Peng, C., Ravi S., Patel, V. K., Momen, A. M., and Moghaddam, S., "Physics of direct-contact ultrasonic cloth drying process," Energy 125, 498-508, ISSN 0360-5442, (2017)

[2] James, A. J., Vukasinovic, B., Smith, M. K., and Glezer, A., "Vibration-induced drop atomization and bursting," Journal of Fluid Mechanics 476, 1-28, (2003).

[3] James, A. J., Vukasinovic, B., Smith, M. K., and Glezer, A., "Vibration-induced drop atomization and the numerical simulation of low-frequency single droplet ejection," Journal of Fluid Mechanics 476, 29-62, (2003).

[4] Ramisetty, K. A., Pandit, A. B., and Gogate, P. R., "Investigations into ultrasound induced atomization," Ultrasonics Sonochemistry 20, 254-264, (2013).

[5] Goodridge, C., Shi, W., Hentschel, H., and Lathrop, D., "Viscous effects in droplet ejecting capillary waves," Physical Review E, 56(1), 472e5, (1997).

[6] Momen, A. M., Gluesenkamp, K. R., Vineyard, E. A., Kisner, R. A., Dryer using high frequency vibration. PCT/US2016/030885. (2015).

[7] Rao, S. S., [Vibration of Continuous Systems], John Wiley \& Sons, Inc., Hoboken, New Jersey, (2007).

[8] Erturk, A., and Inman, D. J., [Piezoelectric Energy Harvesting], John Wiley \& Sons Ltd., West Sussex, United Kingdom, (2011).

[9] Darabi, A., Shahab, S., Leamy, M. J., and Erturk, A., "Bimorph disk piezoelectric energy harvester under base excitation: Electroelastic modeling and experimental validation," Proc. SPIE 9431, Active and Passive Smart Structures and Integrated Systems, 943110, doi: 10.1117/12.2085607, April 2, (2015)

[10] Anton, S., Erturk, A., and Inman, D., "Multifunctional self-charging structures using piezoceramics and thinfilm batteries," Smart Materials and Structures 19(11), 115021, (2010).

[11] Shahab, S., Gray, M. and Erturk, A., "Ultrasonic Power Transfer from a Spherical Acoustic Wave Source to a Free-Free Piezoelectric Receiver: Modeling and Experiment." Journal of Applied Physics, 117, 104903, (2015)

[12] Shahab, S., and Erturk, A., "Contactless Ultrasonic Energy Transfer for Wireless Systems: AcousticPiezoelectric Structure Interaction Modeling and Performance Enhancement." Smart Materials and Structures, 23, 125032, (2014) 


\section{APPENDIX B. MULTIPHYSICS MODELING CONFERENCE PRESENTATION}




\section{Multiphysics modeling of mesh piezoelectric atomizers}

Eric Dupuis ${ }^{\mathrm{a}}$, Ayyoub M. Momen ${ }^{\mathrm{b}}$, Viral K. Patel ${ }^{\mathrm{b}}$, Shima Shahab

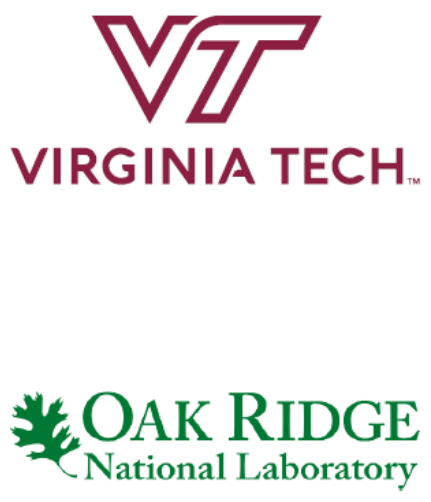

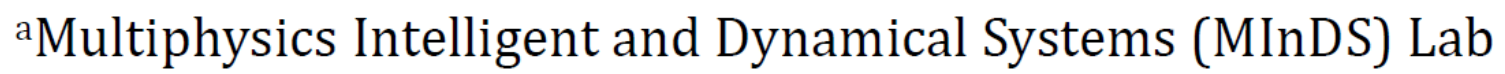
Department of Biomedical Engineering and Mechanics Virginia Tech Blacksburg, VA 24061

${ }^{b}$ Building Equipment Research Energy and Transportation Science Division Oak Ridge National Laboratory Oak Ridge, TN 37830 


\section{Outline}

- Ultrasonic dryer

- Mesh atomizer

- Liquid atomization

- Atomizer model

- Distributed parameter method

- Finite element method

- Experimental validation

- Conclusions and future work

$\underset{\text { VIRGINIA TECH. }}{\text { OAT RIDGE }}$ SPIE 2018 - Denver, CO - 3/7/18 


\section{Ultrasonic Dryer}

- Modified tumble dryer.

- Circuit boards with piezoelectric transducers are embedded in drum walls.

- 240 total transducers.

- Liquid trapped in fabric is atomized via ultrasonic vibrations as a mist.

- The mist is ventilated out of drum, or can condense and flow away.
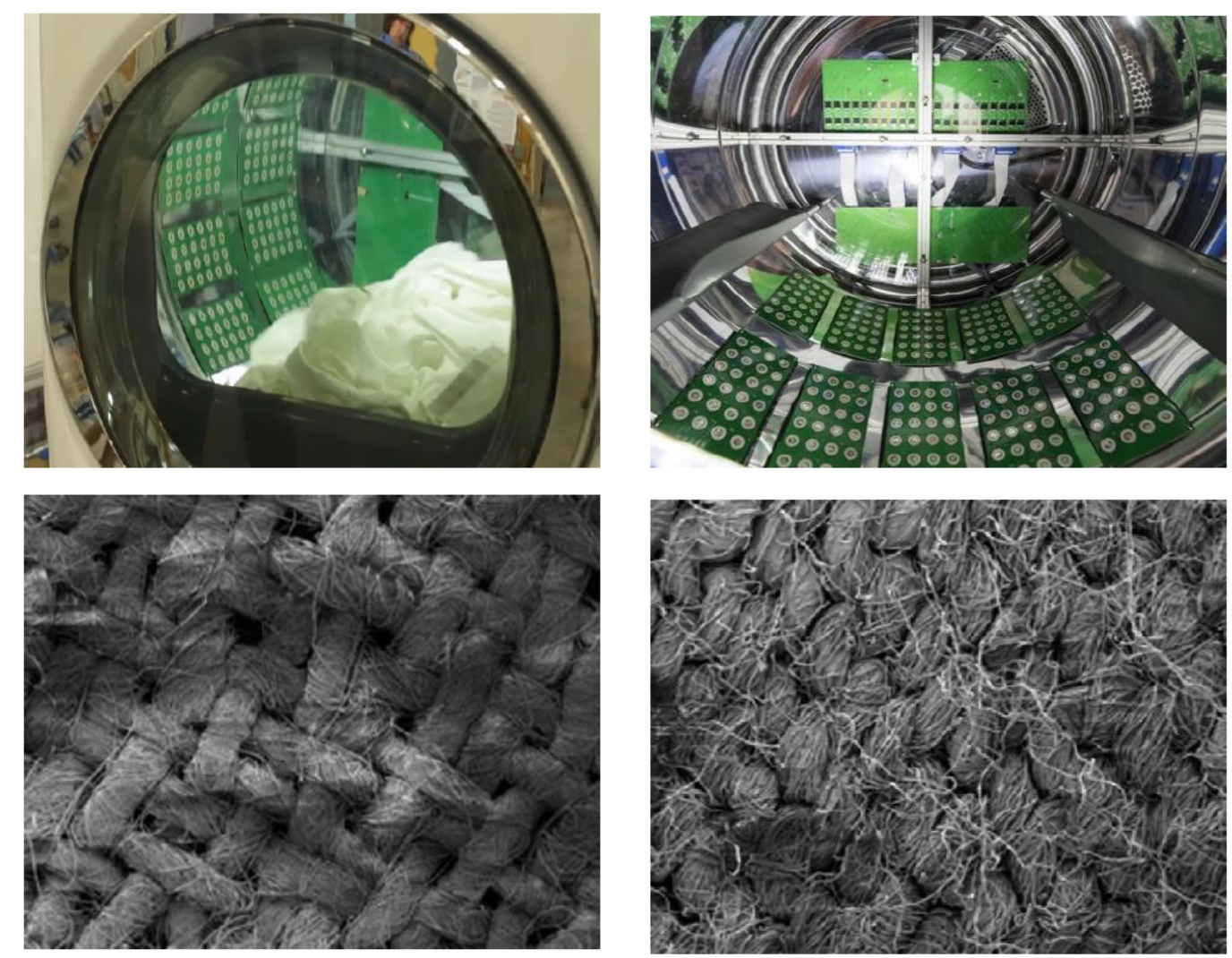

Peng et al. (2017) 


\section{Mesh Atomizer}

- PZT-5A actuation results in transverse vibration of the plate.

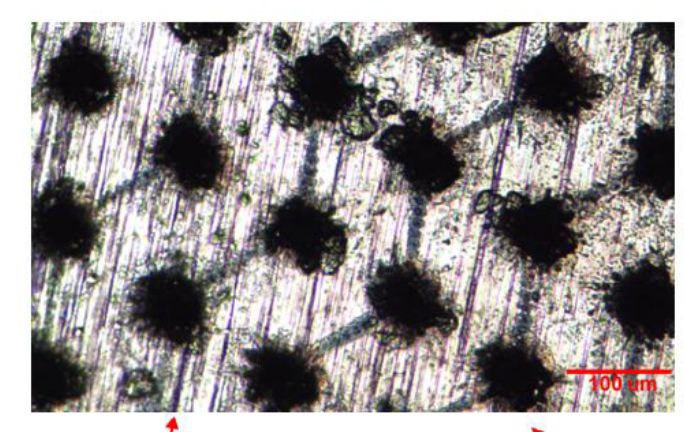

- Liquid droplets in contact with the transducer experience Faraday Excitation.

- Atomized droplets are transported through the meshed center by a pressure difference.

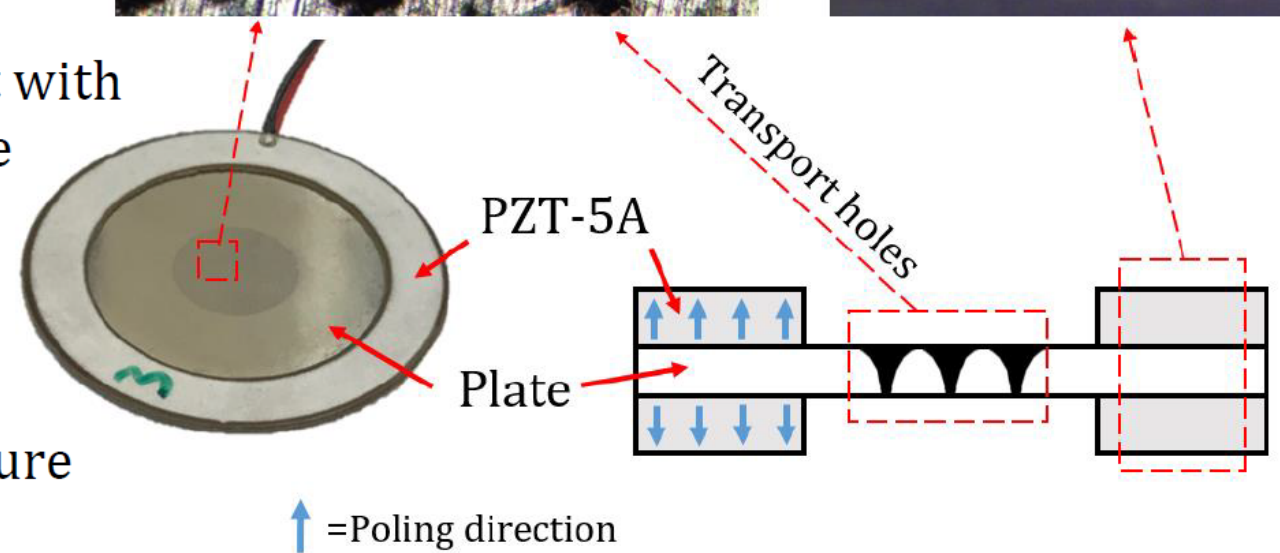

$\underset{\text { VIRGINIA TECH. }}{\mathbb{Z} \text { OAK RIDGenal Laboratory }}$

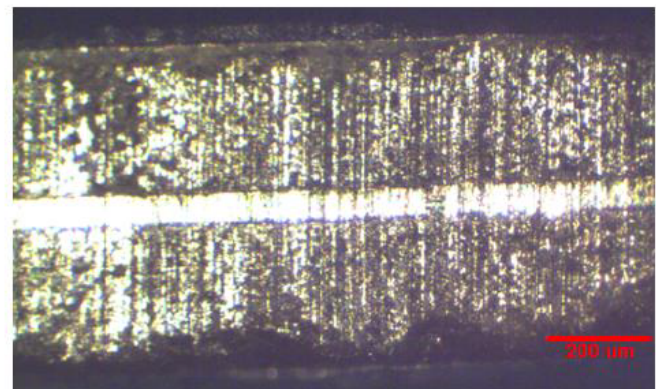

=Poling direction 

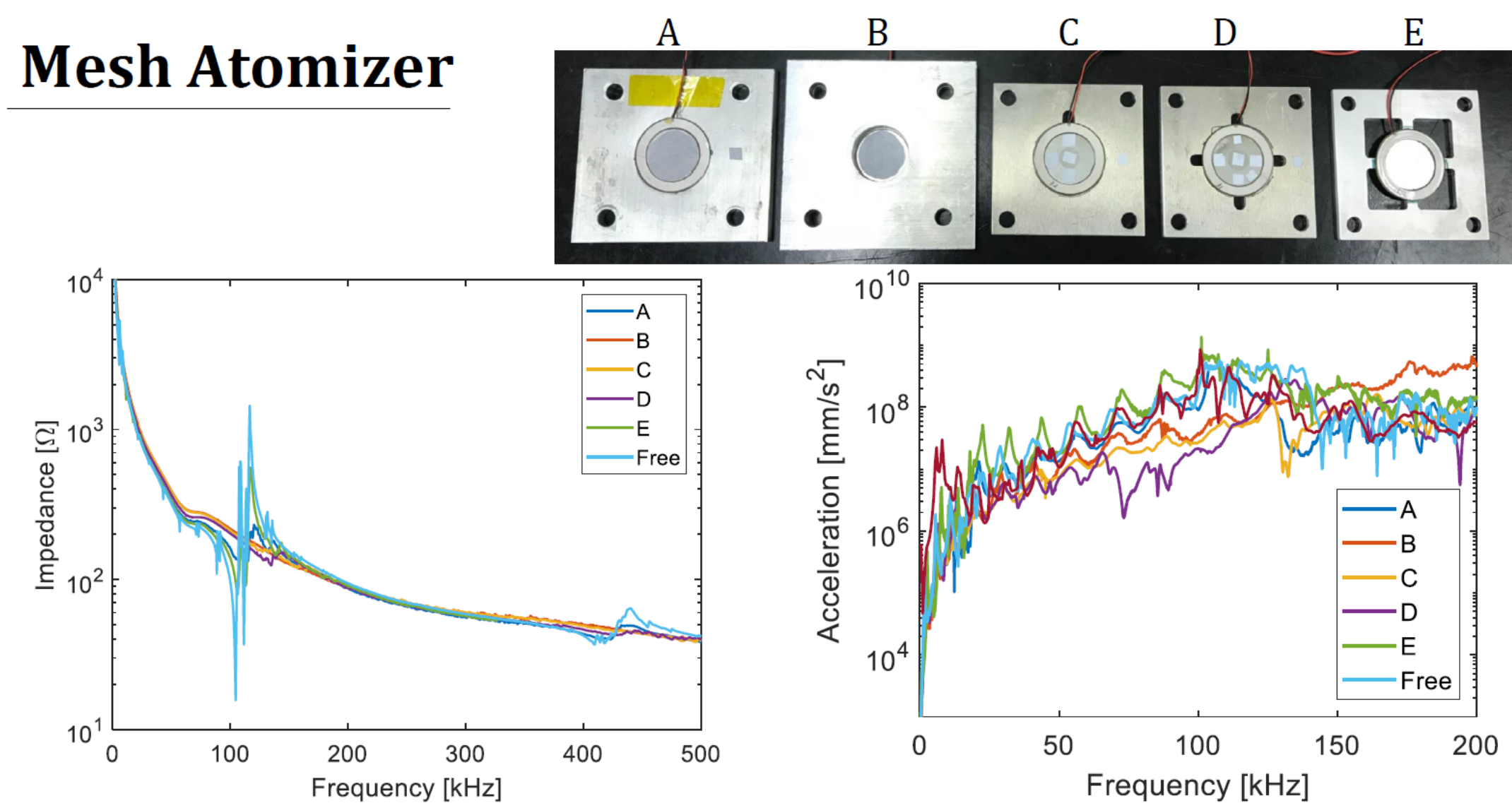

$\underset{\text { VIRGINIA TECH. }}{\text { OAK RIDGE }}$

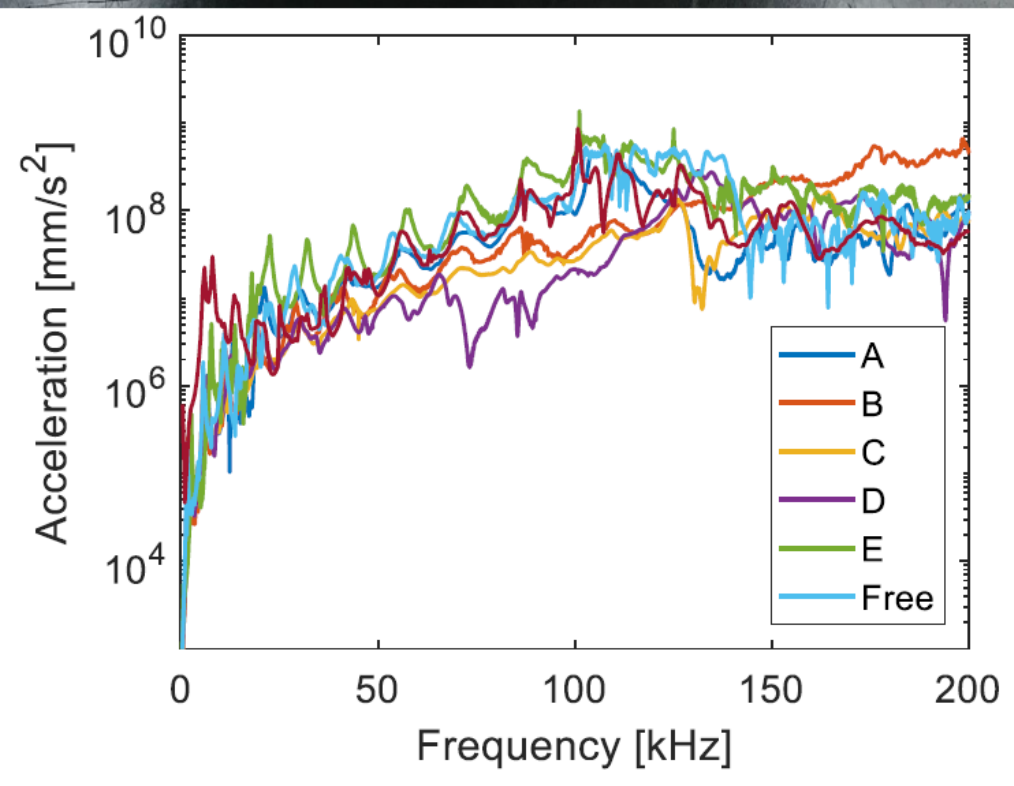




\section{Liquid Atomization}

Capillary Wave Theory

- Standing waves form on liquid surface.

- Wave peaks become extended.

- Capillary pinch-off disconnects tip, ejecting a droplet.

Cavitation Theory

- Shockwaves start at transducer surface.

- Vapor bubbles form from sudden pressure change.

- Cavity is formed from bubble implosion, releasing water as a jet.
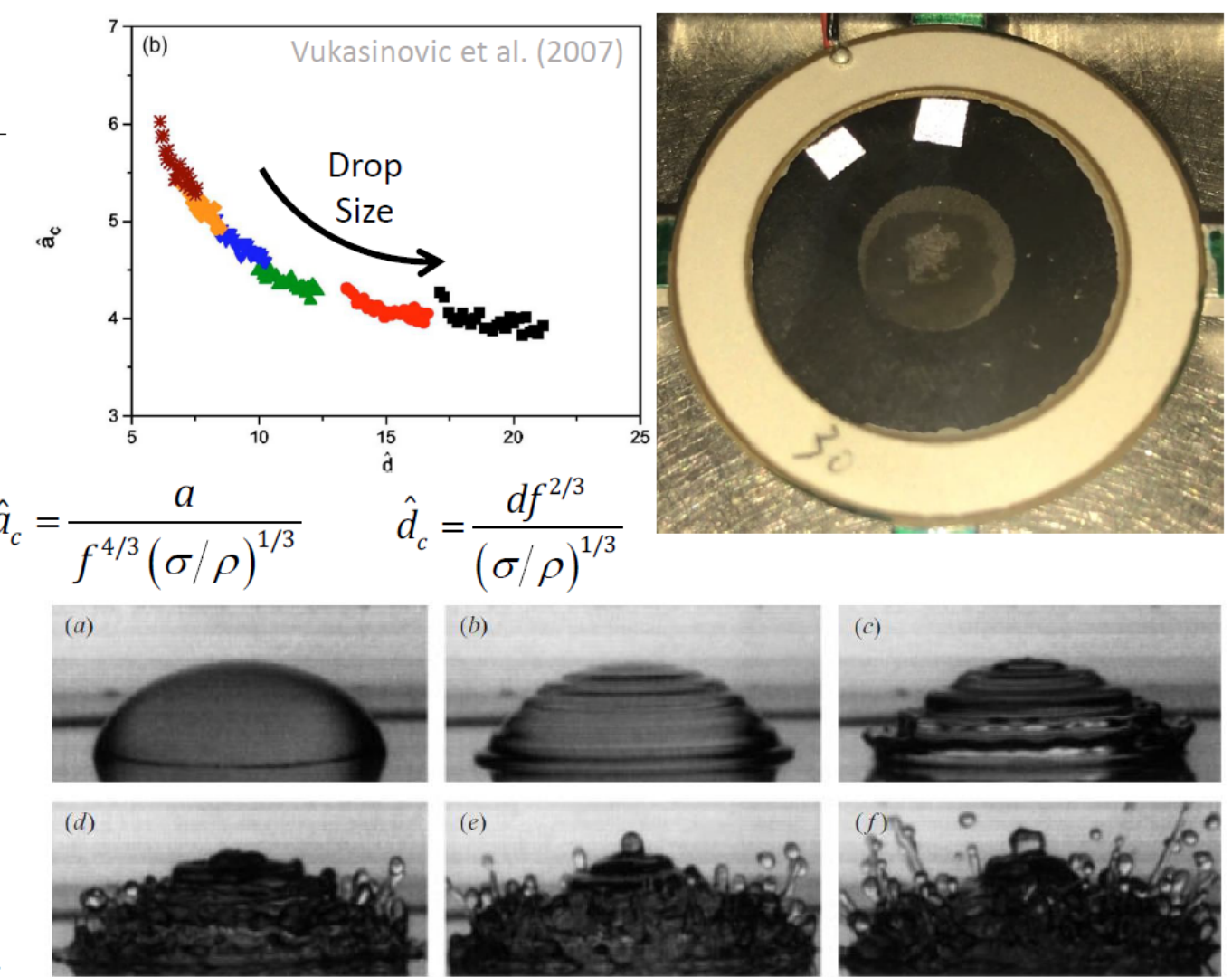
$\underset{\text { VIRGINIA TECH. }}{\text { OAK RIDGE }}$

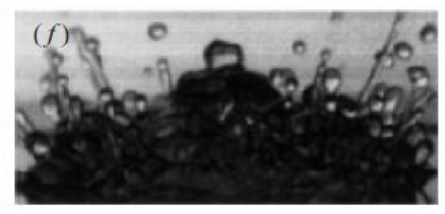

James et al. (2001) 


\section{Plate Model}

Distributed parameter method

$D \nabla^{4} w(r, t)+c_{s} \frac{\partial}{\partial t} \nabla^{4} w(r, t)+c_{a} \frac{\partial w(r, t)}{\partial t}+\rho h \frac{\partial^{2} w(r, t)}{\partial t^{2}}=0$

$w(r, t)=w_{b}(r, t)+w_{r e l}(r, t) \quad w_{b}(r, t)=W_{o} e^{j \omega t}$

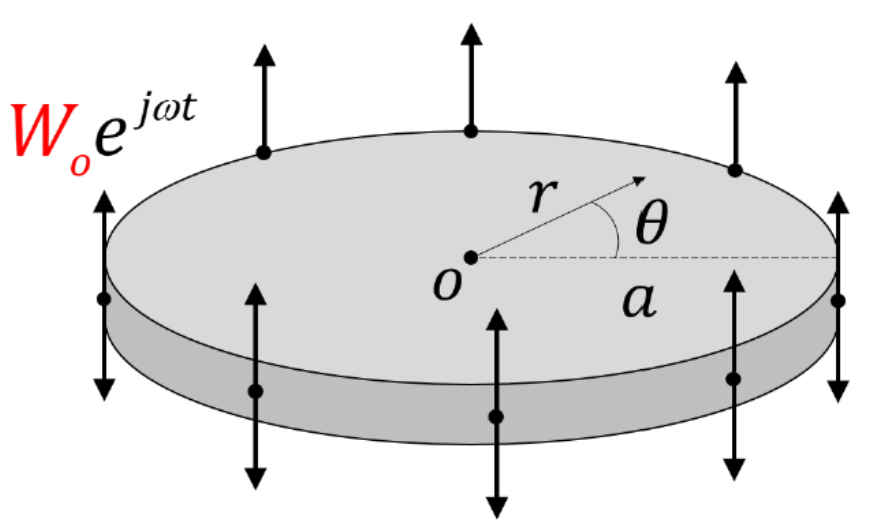

$w_{r e l}(r, t)=\sum_{n=1}^{\infty} \phi_{n}(r) \eta_{n}(t)\left\{\begin{array}{l}\phi_{n}(r)=E_{n}\left[J_{0}\left(\lambda_{n} r\right) I_{0}\left(\lambda_{n} a\right)-J_{0}\left(\lambda_{n} a\right) I_{0}\left(\lambda_{n} r\right)\right] \\ \eta_{n}(t)=A_{n} e^{j \omega t}\end{array}\right.$

$w_{r e l}(r, t)=\sum_{n=1}^{\infty} \phi_{n}(r) \frac{2 \pi \rho h \omega^{2} W_{0}^{a} \int_{0}^{a} r \phi_{n}(r) d r}{\omega_{n}^{2}-\omega^{2}+2 j \zeta_{n} \omega_{n} \omega} e^{j \omega t}$

$$
A_{n}=\frac{f_{n}(t)}{\left(\omega_{n}^{2}-\omega^{2}+2 j \zeta_{n} \omega_{n} \omega\right) e^{j \omega t}}
$$

$f_{n}(t)=2 \pi \rho h \omega^{2} W_{o} e^{j \omega t} \int_{0}^{a} r \phi_{n}(r) d r$ 


\section{Plate Model}

\section{Finite element method}

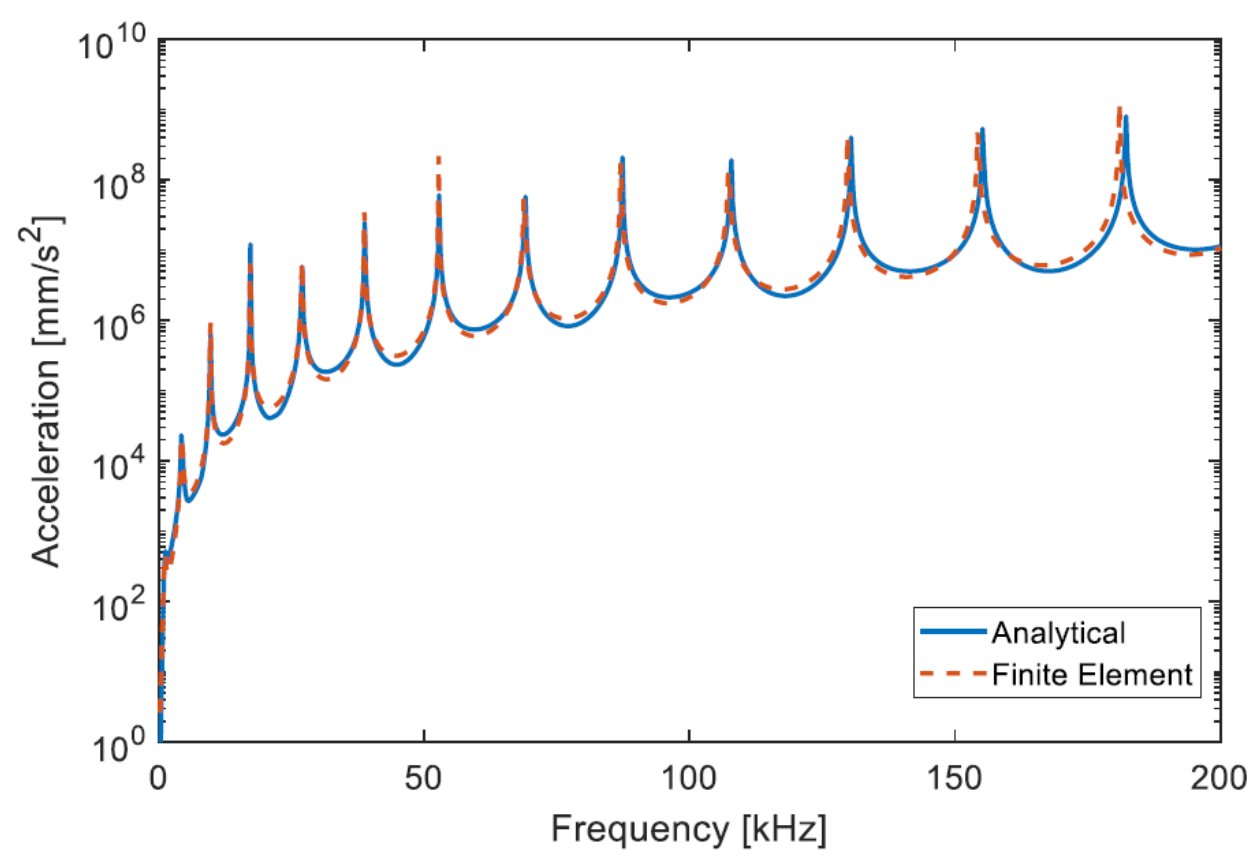

$\underset{\text { VIRGINIA TECH. }}{\text { OAK RIDGE }}$ SPIE 2018 - Denver, CO - 3/7/18
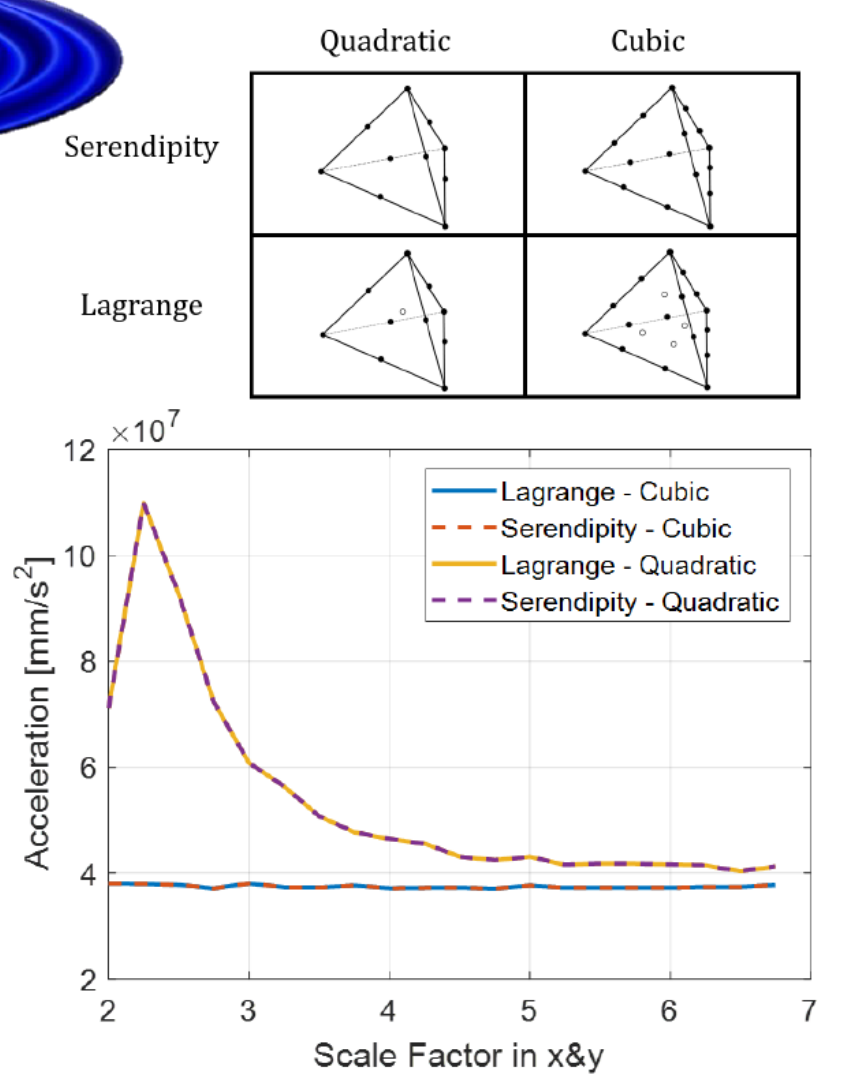


\section{Mesh Atomizer Model}

\section{Finite element method}
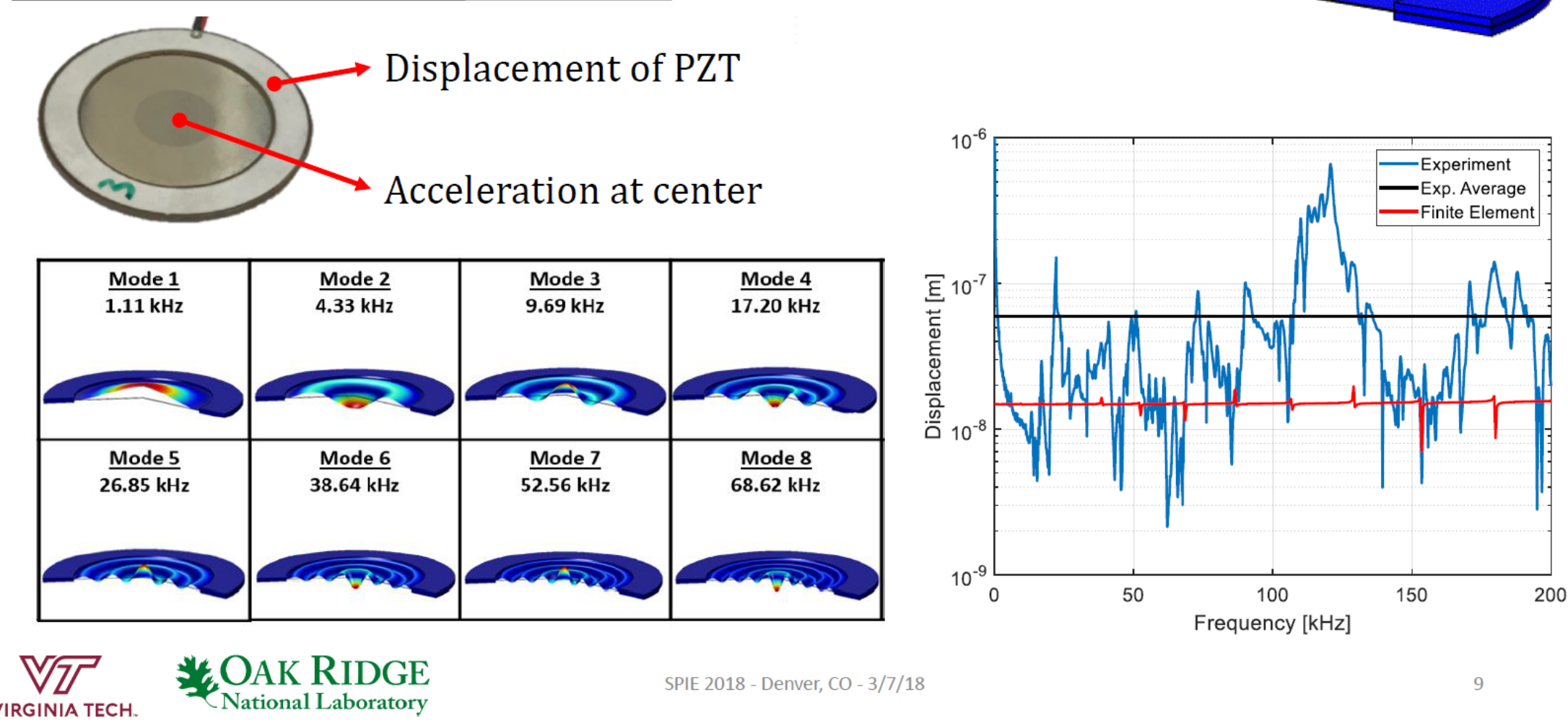

SPIE 2018 - Denver, CO - 3/7/18 


\section{Experimental Validation}
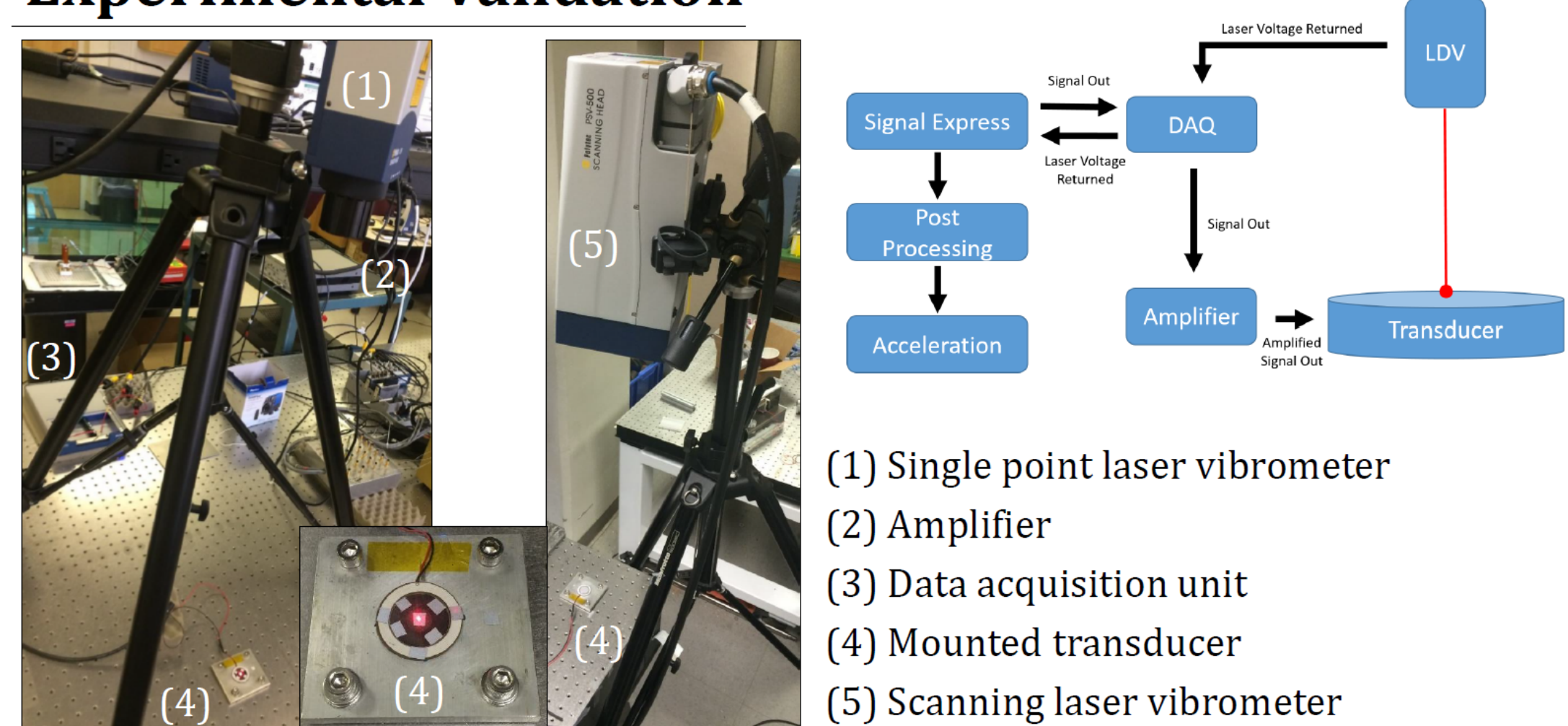

(1) Single point laser vibrometer

(2) Amplifier

(3) Data acquisition unit

(4) Mounted transducer

(5) Scanning laser vibrometer

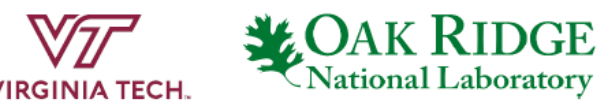




\section{Experimental Validation}

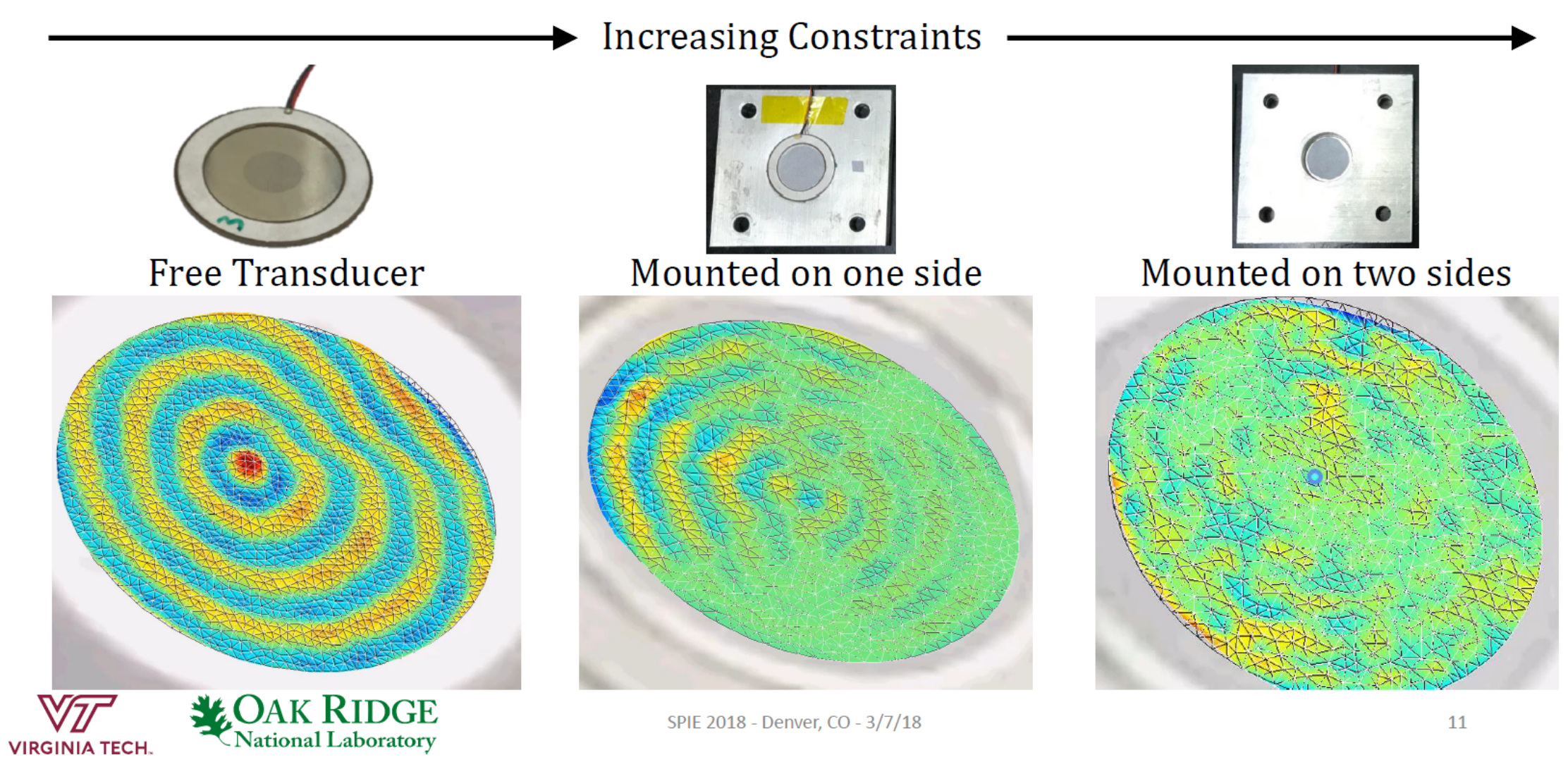




\section{Experimental Validation}

$$
a_{c} \approx 4 f^{4 / 3}(\sigma / \rho)^{1 / 3} \quad \begin{aligned}
& \rho=\text { density }\left[\mathrm{kg} / \mathrm{m}^{3}\right] \\
& \\
& \quad \begin{array}{l}
\sigma=\text { surface tension }[\mathrm{N} / \mathrm{m}] \\
\end{array}
\end{aligned}
$$

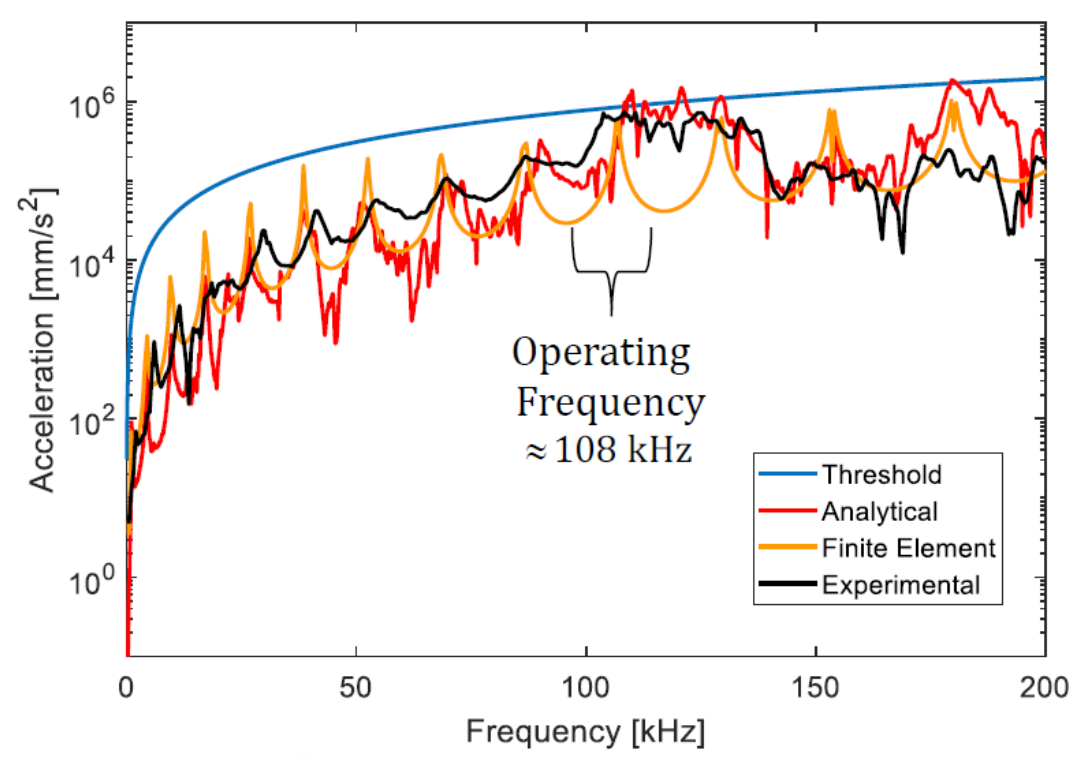

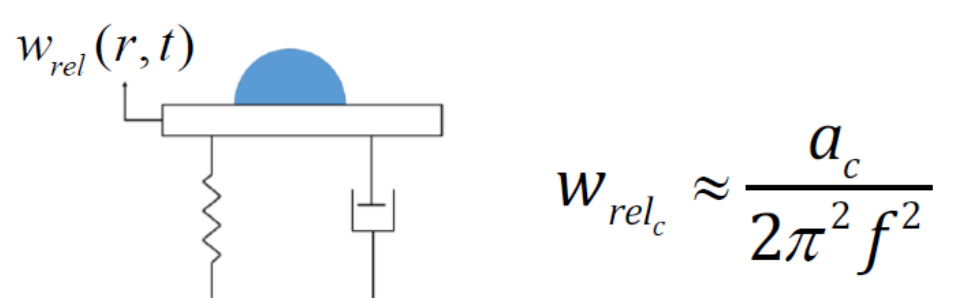

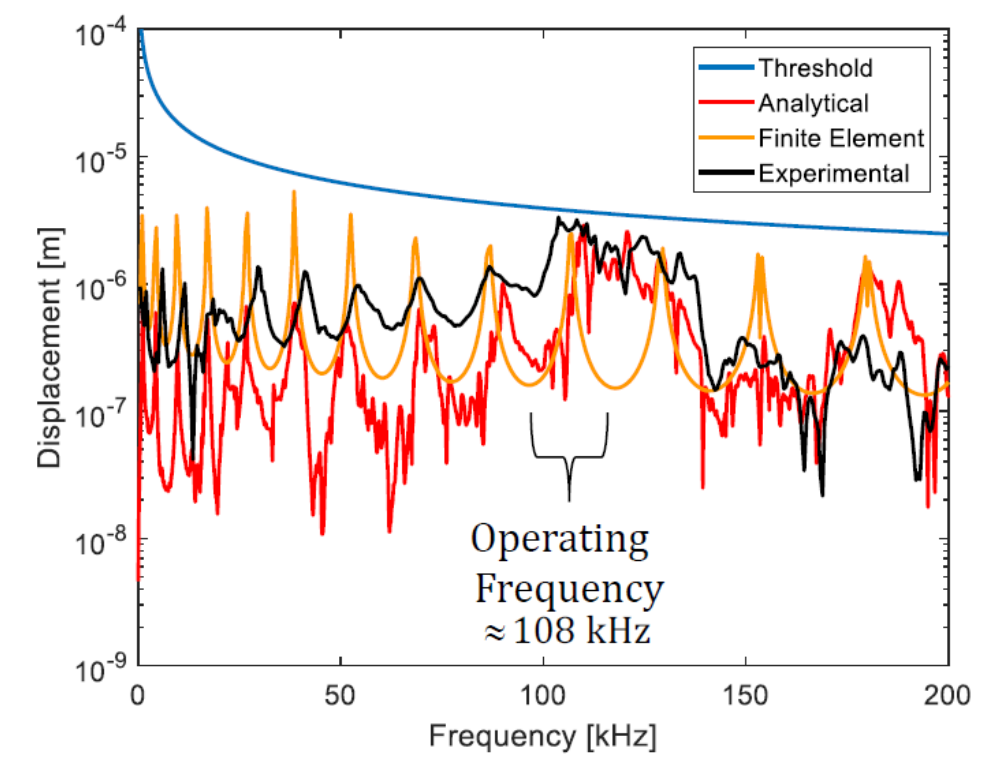

$\underset{\text { VIRGINIA TECH. }}{\text { OAK RIDGE }}$ 


\section{Conclusions \& Future Work}

- Created a model which can successfully predict the acceleration of a piezoelectric transducer.

- Confirmed the model using an analytical expression, finite element software, and experimental measurements

- Future work will model the fluid-structure interactions of a liquid drop exposed to the acceleration of the transducer.

- Predict the atomization time for a drop of known volume.

- Model the interactions of a drop suspended in a fabric

- Predict the atomization time for wet fabric.

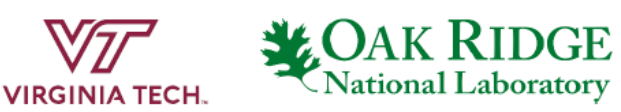




\section{Acknowledgments}

This work was sponsored by the US Department of Energy Building Technologies Office under Contract No. BENEFIT 1632_1520 and NFE-17-06541 with UT-Battelle, LLC. 


\section{FEM Model - Plate Free Vibration}
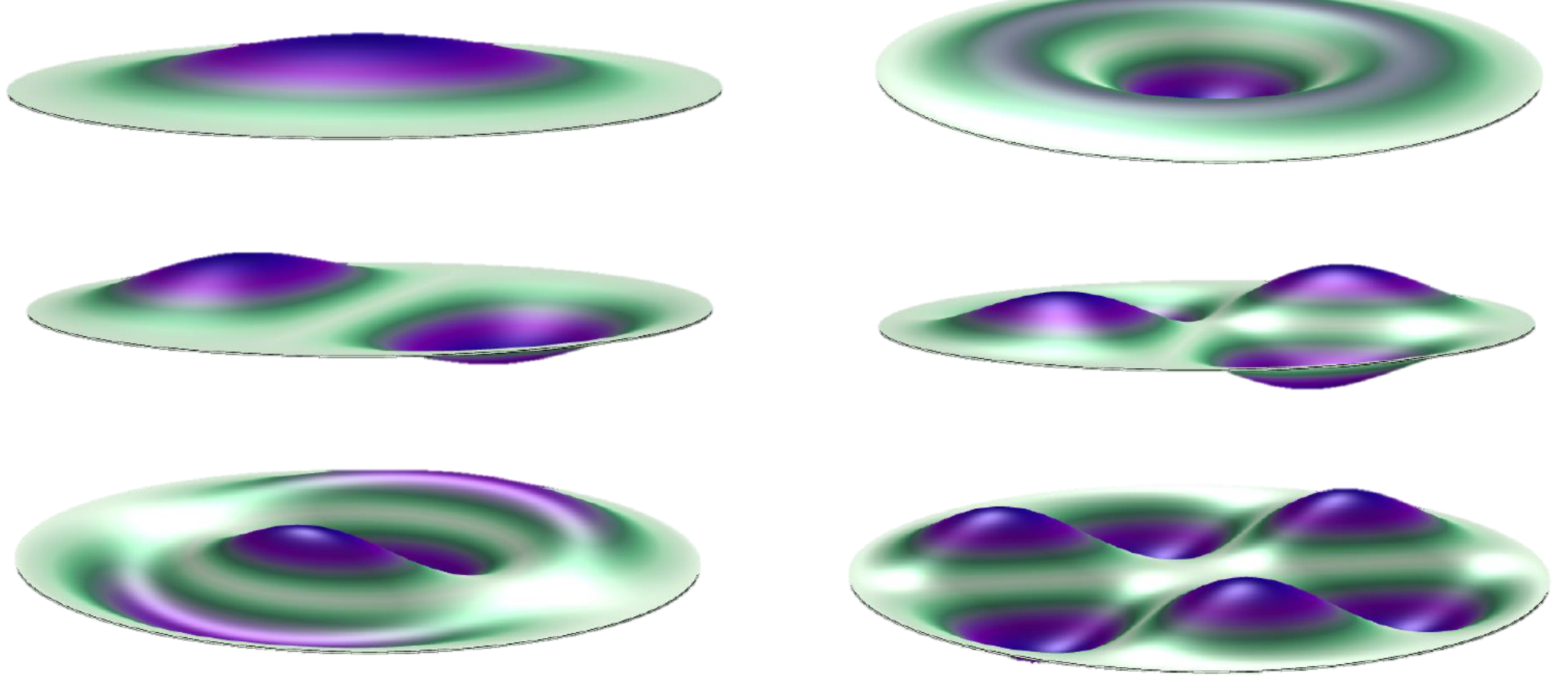

V7 OAK RIDGE VIRGINIA TECH. National Laboratory 


\section{Analytical Model - Plate Free Vibration}

Mode $(0,1), 1.112[\mathrm{kHz}] \quad$ Mode $(0,2), 4.33[\mathrm{kHz}] \quad$ Mode $(0,3), 9.7[\mathrm{kHz}] \quad$ Mode $(0,4), 17.22[\mathrm{kHz}]$
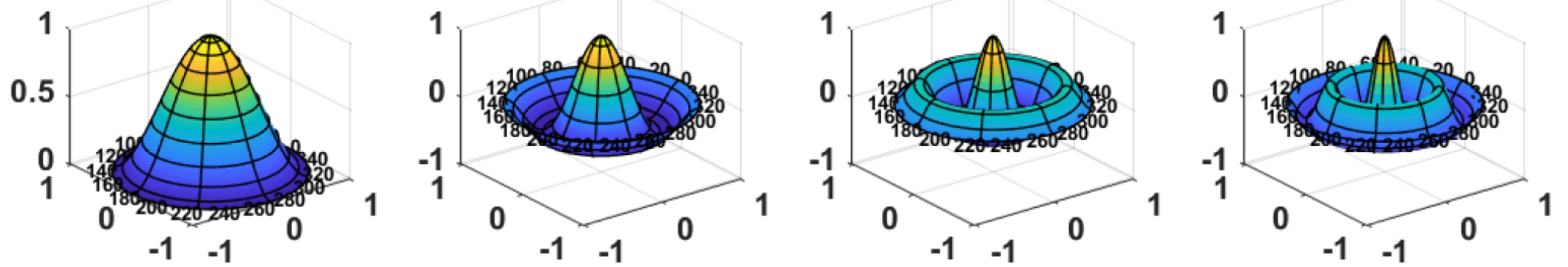

Mode (1,1), 2.314[kHz] Mode (1,2), 6.622[kHz] Mode (1,3), 13.07[kHz] Mode (1,4), 21.67[kHz]
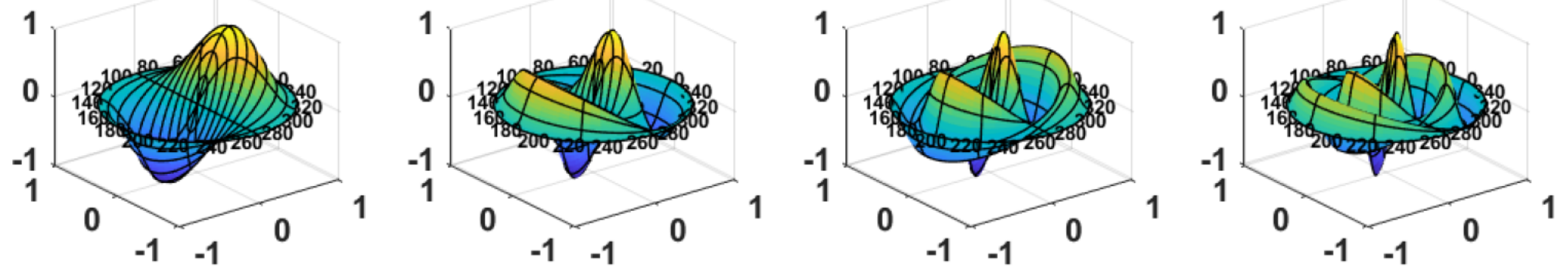

V7F OAK RIDGE 